\title{
6. Systematischer Hauptteil II. Kreativität als kalkulierter Kategorienfehler. Logische Typen und Typen der Logik: Gregory Bateson
}

\subsection{Vorbemerkung: Russells Typentheorie}

\begin{abstract}
Es gibt fast keine formale Theorie, die sich mit analoger Kommunikation befaßt, und insbesondere kein Äquivalent der Informationstheorie. Diese Lücke im formalen Wissen ist hinderlich, wenn wir die verfeinerte Welt der Logik und Mathematik verlassen.
\end{abstract}

Gregory Bateson

Die bisherigen Betrachtungen der unterschiedlichen Weisen des Menschen, Wissen über sich selbst und die Welt zu erwerben und weiterzugeben, legten immer wieder in unterschiedlichen Terminologien eine Grundunterscheidung zwischen zwei kognitiven Verhaltensformen frei: dem ,endlichen Differenzieren' bzw. ,eine Grenze des Unterscheidens ziehen' und ,nicht-endlichem Differenzieren' bzw. ,jeder Unterschied zählt'. Dieses Verhältnis läßt sich auch als Denken und Kommunizieren in diskreten (disjunkten) im Unterschied zu solchen in kontinuierlichen Zeichensystemen beschreiben. Allerdings ist die Rede von „Zeichensystemen“ intern zu differenzieren nach Syntax (Zeichenschema) - und Semantik bzw. Bezugnahmeebene (Zeichenschema plus Referenzbereich: Zeichensystem). Auf beiden Ebenen können Symbolsysteme unterschiedlich „dicht“ bzw. „disjunkt" sein. Eine weitere Differenz, die mit ersterer nur partiell parallel geht, ist jene von Verweisen und Vorweisen, Denotation und Exemplifikation/Ausdruck oder unspezifischer: Sagen und Zeigen. Besagte Verhältnisse wurden im letzten Kapitel unter symbol- und informationstheoretischen Aspekten thematisiert, mit dem Ergebnis, daß jegliche Übersetzung unter ihnen aus symbol-logischen Gründen ein Element des Unkontrollierbaren, Nicht-Determinierten oder ,Freien' aufweist. Dies gründet darin, daß beide Seiten in diesen Übersetzungen niemals restfrei aufeinander reduzier- oder ineinander transformierbar sind - in diesem Sinne also inkommensurabel. In anderer Form hatte sich diese dynamische Beziehung bereits oben im Kant-Kapitel anhand des Verhältnisses von Anschauung und Begriff gezeigt (welches Verhältnis das vermittelnde „Schema“ als ebenso notwendiges wie kreatives Moment auf den Plan rief) ${ }^{1}$, sowie zuvor am Verhältnis

1 Vgl. oben Kap. 4.4.2. 
von Wahrnehmen und Denken bei Aristoteles - was die zentrale verbindende Bedeutung der phantasía, der Imagination bzw. Einbildungskraft hervortreten ließ. In allen diesen Fällen ist es ein aktiver ,Link ' zwischen beiden, der einerseits die komplementären Seiten aufeinander bezieht und der andererseits ein nicht-determiniertes, , freies ${ }^{6}$ Moment in sich birgt.

In dieser Hinsicht läßt sich eine Kontinuität über die vergangenen 2500 Jahre konstatieren. ${ }^{2}$ Vor dem Hintergrund verdient es ein um so höheres systematisches Interesse, daß um 1950 ein alternatives Modell auftrat, ursprünglich in einem ganz anderen Diskussionszusammenhang. Die Rede ist von Gregory Bateson und seiner interdisziplinären Forschergruppe am Department of Sociology and Anthropology der Stanford University, welche Bertrand Russells Typentheorie auf Fragen der Kommunikation angewendet haben. ${ }^{3}$ Batesons den kommunikationstheoretischen Gedanken weiterentwickelnde Theorie bietet nun, wie wir sehen werden, gleichsam ein drittes Modell für das Verhältnis der beiden ,inkommensurablen' Seiten. Bei Kant trafen wir eine kategoriale Trennung ihrer an; zuvor bei Leibniz fand sich eine kontinuierliche Hierarchie - hier nun finden wir so etwas wie eine Hierarchie der Gleichberechtigung, insofern die beteiligten Seiten gleichsam ständig die Plätze tauschen. Aus der Stanforder Variante der Typentheorie entspringt mithin eine neue und provozierend anschauliche Möglichkeit, das kreative Potential und „Grenz-überschreitende" Moment in der Kombination des Heterogenen zu formulieren: gleichsam logisch in Aktion zu sehen.

Das folgende stellt die Elemente von etwas dar, das man als unausgesprochene Kreativitätstheorie Gregory Batesons betrachten könnte. Es wird zunächst sichtbar am Beispiel seiner Spiel-, Lern- und Schizophrenie-Theorie. Da diese Theorien alle verwandt sind und auf demselben theoretischen Fixpunkt basieren, sei zunächst eine kurze Darstellung der Russell'schen Typentheorie vorweggeschickt. Diese klingt auf den ersten Blick kompliziert, beinhaltet aber einen sehr einfachen Grundgedanken.

Russell stellte besagte Überlegungen ursprünglich an, um bestimmte Paradoxienbildungen zu vermeiden, die sich bei reflexiven, also selbstbezüglichen Aussagen innerhalb der mathematischen Mengen-Theorie bilden. ${ }^{4} \mathrm{Zu}$ den historischen Vorläufern solcher Paradoxien zählt das Kreter-Paradox des Epimenides, also die Aussage ,Alle Kreter lügen - ich bin ein Kreter', oder auch allgemeiner: ,Diese Aussage ist falsch'. In Russells mengentheoretischer Reflexion stellt sich das Problem in Form der Frage, ob die Klasse aller Klassen, die nicht bei sich selbst Mitglied sind, selber bei sich Mitglied ist. Der

2 Leibniz' Kontinuum unter den Seiten (welche eine Hierarchie zwischen „analog“ und „digital“ einschloß), fiel allerdings in gewisser Weise aus dem Modell heraus, doch auch hier ist mit der auffallenden Kategorie des „Klaren und Konfusen“ eine vermittelnde Instanz etabliert; vgl. oben Kap. 4.1.2.

3 Zur Geschichte der Anwendung von Russells Theorie auf geistes- und sozialwissenschaftliche Fragen innerhalb der kalifornischen interdisziplinären Forschergruppe vgl. Gregory Bateson, „Vorstudien zu einer Theorie der Schizophrenie“ (1956), wiederabgedruckt in ders., Ökologie des Geistes. Anthropologische, psychologische, biologische und epistemologische Perspektiven, S. 270, Fußnote 1. (Originalausgabe: Steps to an Ecology of Mind (1972).

4 Vgl. für das folgende Bertrand Russell, Die Philosophie des Logischen Atomismus. Aufsätze zur Logik und Erkenntnistheorie 1908-1918, darin: „Mathematische Logik auf der Basis der Typentheorie“, insbes. S. 38 ff. Vgl. ferner Bateson, Ökologie des Geistes, S. 363 ff. 
Versuch der Antwort führt in ein nicht endendes logisches Oszillieren: in ein Paradox. ${ }^{5}$ Um dieses zu unterbinden gliedert Russell Aussagenteile bzw. „Objekte“ (Variablen) in Typen unterschiedlicher Abstraktionsklassen: Mengen und ihre Elemente bzw. Klassen und ihre Mitglieder. Das Grundprinzip dieser Aufgliederung lautet, daß keine Gesamtheit Elemente enthalten kann, die durch diese selbst definiert sind. ${ }^{6}$ In anderen Worten, keine Menge oder Klasse kann bei sich selbst Mitglied sein; ferner kann auch umgekehrt kein Element selbst die ganze Klasse sein. Vielmehr gehören die Elemente der Klasse und die Klasse selber unterschiedlichen Abstraktions-Ebenen, in diesem Sinne unterschiedlichen logischen Typen an. (Angewendet auf normale Sprachen heißt das etwa: die Klasse aller weißen Katzen ist selbst weder eine Katze noch ist sie weiß, auch ist die Klasse der NichtKatzen keine Nicht-Katze, und die Partitur eines Stücks Musik ist selbst nicht Musik.) Russell gliedert dabei sein typentheoretisches Modell wie folgt - und dieses wird später von Bateson verändert aufgegriffen. Den ersten oder untersten Typ bilden „Individuen“, welche qua Individuation keine Mengen als Unter-Elemente enthalten können. Sie sind der sogenannte erste logische Typ, die Terme elementarer Aussagen beinhaltend: immer Partikel, atomare Einheiten, keine Relationen. ${ }^{7}$ (Man kann - in Abwandlung von Bateson und Watzlawick - diesen ersten logischen Typ auch als Aussagen nullter Ordnung bezeichnen: sie liegen vor jeder Ordnung: nämlich vor den relationalen Beziehungen von Typen-, Mengen- oder Klassenaussagen.)

Auf diesen nun basieren alle weiteren Schritte:

„Aussagen über diese Individuen, also solche, die nur Individuen als gebundene Variablen enthalten, werden wir Aussagen erster Ordnung nennen. Sie verkörpern den zweiten logischen Typ." ${ }^{\text {8 }}$

Damit ist die Relation des „über“ eingeführt; in dem Moment, wo eine Aussage eine ,über' eine andere ist (diese zum Gegenstand hat), sind zwei logische Typen im Spiel. (Die Klasse der weißen Katzen ist ein Prädikat, das ,über“ weiße Katzen ist und verkörpert damit einen anderen Typ als die Katzen selber.) Solche Aussagen über den ersten logischen Typ verkörpern den zweiten logischen Typ und sind Aussagen erster Ordnung. ${ }^{9}$ Von hier aus geht die hierarchische Schichtung entsprechend weiter:

5 Vgl. hierzu Batesons Aussagen in dem Werk, das er 1951 in den USA zusammen mit dem Schweizer Psychiater Jürgen Ruesch verfaßt hat: Jürgen Ruesch/Gregory Bateson, Kommunikation. Die soziale Matrix der Psychiatrie. Kap. 7 („Information und Kodifikation“), insbes. 217 ff. Zum Paradox nach Bateson: „Ein Mann klassifiziert Entitäten in Klassen, und jede Klasse, die er definiert, führt eine Klasse von anderen Entitäten ein, die nicht ihre Elemente sind. Er stellt fest, daß die Klasse von Elefanten nicht selbst ein Elefant ist, aber daß die Klasse von Nichtelefanten selbst ein Nichtelefant ist. Er verallgemeinert, daß manche Klassen Elemente ihrer selbst sind und andere es nicht sind. Dadurch schafft er zwei umfassendere Klassen von Klassen. Dann muß er entscheiden: Ist die Klasse der Klassen, die nicht ihre eigenen Elemente sind, ein Element ihrer selbst? ... Wenn die Antwort ,ja' ist, dann muß sie ,nein' sein, aber wenn sie ,nein' ist, dann muß sie ,ja' sein.“ Ebd. S. 217.

6 Vgl. Russell, Die Philosophie des Logischen Atomismus, S. 38.

7 Vgl. Russell, ebd. S. 39.

8 Ebd.

9 Dies wirkt nur auf den ersten Blick verwirrend: Da Elemente noch keine Aussagen enthalten, ist der Index ihrer - als Typen - immer höher als der der Aussagen, welche zwei Typen kombinieren. 
„Wir können nun neue Aussagen bilden, in denen Aussagen erster Ordnung als gebundene Variable vorkommen. Sie werden Aussagen zweiter Ordnung genannt, und sie verkörpern den dritten logischen Typ. So behauptet etwa Epimenides eine Aussage zweiter Ordnung, wenn er sagt ,Alle von mir behaupteten Aussagen erster Ordnung sind falsch'. Er kann das wahrheitsgemäß behaupten, ohne eine wahre Aussage erster Ordnung zu behaupten. Daher kommt kein Widerspruch zustande. - Der obige Prozeß kann unbegrenzt fortgeführt werden. Der $\mathrm{n}+1$ te Typ besteht aus Aussagen nter Ordung, die derart sind, daß sie Aussagen n-1ter Ordnung als gebundene Variable enthalten, aber keine Aussagen höherer Ordnung. Die so gewonnenen Typen schließen einander aus. "10

Dieser letzte Satz artikuliert Russells fundamentale Absicht. Zwischen beiden Typen gibt es keinen Übergang, d. h. auch keine gemeinsam besessenen Mitglieder. Folglich kann sich jede Aussage, die auf einer bestimmten Ebene gemacht wird, immer nur auf die logische Abstraktionsebene darunter beziehen, auf den niederen Typ also, nie gleichzeitig auch auf sich selbst. Damit fällt die Möglichkeit selbstbezüglicher Aussagen weg und so die Basis von Paradoxien.

Um auf das Beispiel zurückzukommen: die Konstruktion der Klasse aller weißen Katzen impliziert logisch eine Aussagen-Ebene, die selbst außerhalb der Klasse der weißen Katzen steht und sowohl über ihr situiert ist wie sie über sie ist; und sie impliziert die Möglichkeit anderer Farben und anderer Lebewesen. Dies beinhaltet daß die Klasse selbst weder weiß sein kann noch schnurren. Dieser Punkt ist logisch bedeutsam und hat vielfältige Konsequenzen: so besagt er, daß ein Phänomen oder eine Gruppe von Phänomenen nie von ihr selbst aus, sondern immer nur von einer höheren Abstraktions- oder Organisationsebene aus beschrieben werden kann. ${ }^{11}$ Und umgekehrt: daß jede Beschreibung oder Analyse eines Phänomens unweigerlich den Wechsel der Ebene, eine Distanzierung, ein Herausbegeben impliziert, will es nicht als selbstbezüglich in Paradoxa geraten. Später wurde diese Figur systemtheoretisch dahingehend gewendet, daß jede intendierte Selbstbeobachtung immer eine weitere Beobachterperspektive impliziert, die über diese hinausreicht (etwa in Form eines externen Beobachters/Coachs/Therapeuten/Über-Ichs welcher/s auch internalisiert werden kann). In andern Worten: wenn ein Kreter sagt, „Alle Kreter lügen“, so umfaßt die Aussage nicht auch die Position des Sprechers - selbst wenn der Sprecher Kreter ist. „Alle Kreter“ kann dieser Position zufolge nur von außerhalb der Gruppe der Kreter gesagt werden. ${ }^{12}$ Hier zeigt sich schnell, daß die Alltagssprache nicht typentheoretisch organisiert ist.

10 Ebd.

11 In Anthony Wildens Worten: „,no communication can be properly defined or examined at the level at which the communication occurs". System and Structure. Essays in Communication and Exchange, S. 113. Noch deutlicher wird der philosophische Stellenwert solcher Analysen, wenn wir Wittgensteins Beobachtung als einen Ausdruck ihrer sehen: „Wenn es einen Wert gibt, der Wert hat, so muß er außerhalb alles Geschehens und So-Seins liegen. Denn alles Geschehen und So-Sein ist zufällig. Was es nicht zufällig macht, kann nicht in der Welt liegen, denn sonst wäre dies wieder zufällig. Es muß außerhalb der Welt liegen." Ludwig Wittgenstein, Tractatus Logico-Philosophicus, 6.41.

Diese logische Struktur wird von dem Umstand verkörpert, auf den wiederum Wittgenstein aufmerksam machte, daß ein Auge sich selbst nicht sehen kann, in seinem Gesichtsfeld nicht vorkommt. Vgl. Tractatus 5.632/3: „nichts am Gesichtsfeld läßt darauf schließen, daß es von einem Auge gesehen wird“. Kommt ein Auge in einem Gesichtsfeld vor, so ist es notwendig nicht das Auge, von dem aus 
In der Verletzung eben dieses wechselseitigen Ausschlußverhältnisses liegt nun die Basis des Konzepts vom „logischen Fehlschluß“, als immer dann auftretend, wenn die Grenze bzw. die Diskontinuität zwischen logischen Typen oder Aussagen-Ordnungen durchbrochen wurde: wenn beide sich mischen. Ein Mensch, der „Obst“ verlangt, jedoch in Obsthandlungen zu seiner wachsenden Verzweiflung nur Bananen, Äpfel, Kirschen etc. vorfindet, macht diesen Fehler (was beinhaltet, daß viele von uns ihn unbewußt häufig machen ${ }^{13}$ ), und im folgenden werden noch verschiedene andere Beispiele für pathologische und kreative Brüche dieser Art betrachtet.

In die Sprachphilosophie und ,philosophy of mind“ wurde das Konzept des „,category mistake“ zuerst von Gilbert Ryle in seinem 1949 erschienenen Buch ,,The concept of mind" hineingetragen. Kategorienfehler logischer Art sind es, in denen laut Ryle zentrale philosophische Irrtümer der ,philosophy of mind ' gründen, ${ }^{14}$ und er sah eine philosophische Grundaufgabe darin, ,,anzuzeigen, zu welchen logischen Typen die entsprechenden Begriffe eigentlich gehören“. ${ }^{15}$ Russells mathematisch-mengentheoretische Typen-Unterscheidung wurde also in die Philosophie importiert, und sie ist seit Ryle daraus nie wieder völlig verschwunden.

Früher noch wurden Russells Ideen jedoch von Gregory Bateson in die Geistes-, Sozial- und. Kommunikationswissenschaften übertragen; dies geschah wesentlich auf Anregung Norbert Wieners. ${ }^{16}$ Wiener, der u. a. bei Russell studierte hatte und zu des-

gesehen wird. Und ist der Sprecher ein Kreter, so ist das Kreter-Sein nicht die logische Perspektive, von der aus der Satz gesprochen wird.

13 In Beziehungen beispielsweise sowie etwa bei der Wahl von Berufen oder Reisezielen kommen Fehler dieser Art unbewußt häufig vor. - Man könnte umgekehrt sagen, daß Verliebtheit darin besteht, diesen Kategorienfehler zu machen: wir sind so lange verliebt, wie eine Kirsche für uns in der Tat „Obst" repräsentiert.

14 Vgl. Gilbert Ryle, Der Begriff des Geistes, S. 13. - Ryles Beispiele für Kategorienfehler verkörpern auf amüsant wörtliche Weise seine Kritik an einer Konzeption des „Geistes“ als eines verdinglichten „Gespensts in der Maschine“: „Ein Südseeinsulaner sieht seinem ersten Fußballspiel zu. Man erklärt ihm die Funktion des Torwarts, der Stürmer, Verteidiger, des Schiedsrichters usw. Nach einer Weile sagt er: ,Aber es fehlt jemand, der den berühmten Mannschaftsgeist beisteuert““. Ebd. S. 15

15 Vgl. ebd. S. 5, Hvh. S. M. Es beinhaltet „Kategoriengewohnheiten durch Kategoriendisziplin zu ersetzen“, ebd.

16 Bateson hatte Wiener 1946 auf einer der Macy-Konferenzen zur Kybernetik kennengelernt und ad hoc als seinen selbstgewählten Mentor adoptiert. Zu den Gründen und Umständen der Bateson'schen Teilnahme an den Macy-Konferenzen vgl. Bateson Ökologie des Geistes, 10 f. Die Vorgeschichte der Übertragung der Kybernetik auf Sozial- und Verhaltenswissenschaften beschreibt Lawrence S. Bale in: „Gregory Bateson, Cybernetics, and the social/behavioural Sciences“: „Even in the so$\mathrm{cial} /$ behavioural sciences, references to mind remained suspect. Building on the work of Norbert Wiener, Ross Ashby and Warren McCulloch, Bateson realized that it is precisely the mental process of mind which must be investigated. Thus, he formulated the criteria of mind and the cybernetic epistemology that are pivotal elements in his ,ecological philosophy'. In fact, he referred to cybernetics as an epistemology, e. g. the model, itself, is a means of knowing what sort of world this is, and also the limitations that exist concerning our ability to know something (or perhaps nothing) of such matters. As his work progressed, he proposed that we consider Epistemology as an overarching discipline of the natural sciences ... a meta-science whose parameters extend to include the science of mind in the widest sense of the word." Ebda S. 27 f. , Hvh. S. M. 
sen „kybernetischen“ Inspirationen dezidiert Leibniz zählte ${ }^{17}$, machte Bateson mit der Typentheorie bekannt ${ }^{18}$, der sie wiederum in seine interdisziplinären Arbeitszusammenhänge hineintrug: neben der erwähnten Stanford-Gruppe war dies vor allem das Mental Research Institute in Palo Alto. Übertragen von mathematischen Problemen auf reale menschliche Kommunikationsabläufe zeigt sich das Phänomen einer solchen Typisierung von Mitteilungen als eines des „Framings“ oder Rahmens. ${ }^{19}$ Indem ein klassifizierender Rahmen um eine bestimmte Gruppe von Mitteilungen gezogen wird (,Dies ist $\mathrm{Spa}^{\star}{ }^{\star}$, ,Das ist ein Befehl', ,Das ist Ironie', ,Ich liebe Dich'), definiert dieser, zu welcher Klasse von Mitteilungen ein Verhalten zu zählen ist und ermöglicht damit erst dessen Interpretation. Der Rahmen gehört jedoch nicht selbst zu dieser Art Mitteilungen, und er muß auch keineswegs notwendig verbal gezogen werden..$^{20}$ Er operiert von einer „höheren" (Abstraktions-)-Ebene aus.

An diesem Punkt nun beginnen in der realen Kommunikation aufschlußreiche Probleme. So klar die Ebenen-Trennung in der Theorie ist, so verschwommen - und in dieser Verschwommenheit potentiell hoch wirksam - ist sie potentiell in der Praxis. ${ }^{21}$ Eine rahmende (Meta-)Mitteilung alias ,Aussage zweiter Ordnung ${ }^{6}$ kann leicht als Aussage erster Ordnung mißverstanden werden: etwa wenn ein ritualisierter Angriff zwischen zwei Stämmen (Ritus $=$ Rahmung) zu Zwecken eines Friedensschlusses als ein tatsächlicher Angriff aufgefaßt wird und einen Gegenangriff provoziert. ${ }^{22}$ Genau ein solcher Bruch der geforderten Diskontinuität logischer Ebenen ist nun laut Bateson gerade die Basis nicht nur für Pathologien und Eskalationen im menschlichen Denken und Verhalten, sondern auch für wichtige Formen kreativer Entwicklung und Produktivität. ${ }^{23}$ Die Vielfalt dessen sei im folgenden näher beleuchtet.

17 Vgl. etwa Norbert Wiener, „Zurück zu Leibniz!“ von 1932, in ders., Futurum Exactum. Ausgewählte Schriften zur Kybernetik, S. 93-104.

$18 \mathrm{Zu}$ den Hintergründen dieser Bekanntschaft und Einflüsse sowie der Rolle der Macy-Konferenzen für Batesons intellektuelle Entwicklung vgl. Max Visser, „Gregory Bateson on Deutero-Learning and Double-Bind: A Brief Conceptual History“.

19 Erving Goffman hat diesen Gedanken in seiner eigenen „Frame-Analysis“-Theorie weitergeführt; vgl. ders., Frame Analysis; an essay on organization of experience.

20 Ein Zwinkern oder ein bestimmter Tonfall beispielsweise kann ihn ebenfalls stiften.

21 Dazu folgendes Erlebnis: Am Tag nach der Trauung erklärte auf einem Ausflug der frisch gebackene Ehemann der Hochzeitsgesellschaft so beiläufig wie dezidiert: „Übrigens, der gestrige Standesbeamte war gar keiner, war nur ein von uns organisierter Schauspieler." Hier galt es, seine neue Rahmung der rituellen Handlung des Heiratens (als: das war Theater, also Spiel) nun wieder daraufhin zu überprüfen, ob diese neue Meta-Mitteilung nun ihrerseits Ernst oder „,nur“ ein weiterer Fall von „Spiel“" war. In diesem Fall machte zweimal ,dies ist Spiel“ aus der Handlung wieder Ernst. (In gewisser Weise ähnelt das der doppelten Verneinung, die wiederum zur Bejahung führt.) Es ist potentiell Ernst, sofern es für die frisch Angetraute wiederum möglicherweise einen eigenen Rahmen um die eben stattgebabte Handlung zieht.

Die Möglichkeit, in der „Rahmung“ Fehler zu machen bzw. in der Rahmung zu lügen bzw. zu täuschen, zeigt der Film „Das Leben der Anderen“ (2006) von Florian Henckel von Donnersmarck in der sprechenden Szene, wo ein Stasi-Mann in der Kantine seinen Kollegen ermutigt, einen Regimekritischen Witz zu erzählen - mit existentiellen Folgen.

23 Bateson spitzt dies dergestalt zu, daß „Russells Regel nicht aufgestellt werden kann, ohne daß sie verletzt wird“, Bateson, Ökologie des Geistes, S. 256. 


\title{
6.2 Vom ,Bite“ zum ,Nip“: Die Entstehung der Negation und der arbiträren Zeichen aus dem spielerischen Biß
}

\begin{abstract}
Nicht nur meinen spielende Tiere nicht ganz, was sie sagen, sondern sie kommunizieren auch über etwas, das es gar nicht gibt. Auf der menschlichen Ebene führt dies zu einer unermeßlichen Vielfalt von Komplikationen und Verdrehungen im Bereich von Spiel, Phantasie und Kunst.
\end{abstract}

Gregory Bateson

Evidenterweise liegt eine Aufgabe jeglicher Theorie des Denkens und Erkennens in der Aufgabe, logische Irrtümer und ihre Konsequenzen zu untersuchen. Doch wo Grenzen bestimmt werden, entstehen logische Lockungen, theoretische Attraktoren. So hat es nicht lange gedauert, bis die Diagnose logischer Fehlschlüsse nicht nur als Analysemittel für Denk-Fehler, Paradoxien und Kommunikations-Pathologien, sondern zugleich und wesentlicher zur Beschreibung der produktiven Leistungen der Kultur diente. Eben dies geschah, wie bereits angedeutet, in den interdisziplinären Forschergruppen um Gregory Bateson: zunächst in Stanford, später im kalifornischen Mental Research Institute Palo Alto. Betrachten wir zunächst die symboltheoretischen und epistemologischen Implikationen, die sich in der tierischen und menschlichen Kommunikation des „Spiels“ finden. Auf der Basis der so herausgearbeiteten symbol- und kommunikations-logischen Überlegungen geht die Betrachtung in den nächsten Unterkapiteln über zu den strukturell verwandten Phänomenen aus Pathologie, Lerntheorie, Kognition und Kreativität.

Der Anthropologe, Biologe, Soziologe und Erkenntnistheoretiker Gregory Bateson ${ }^{24}$ leitete mit seiner Theorie der (Meta-)Kommunikation eine Betrachtung menschlicher (und tierischer) Erkenntnis- und Verständigungsformen ein, die von Watzlawick/Beavin/ Jackson, Anthony Wilden, später auch Humberto Maturana und Francisco Varela weiterentwickelt bzw. ausgeweitet wurden. ${ }^{25}$ Bateson analysierte typentheoretisch zunächst so verwandte Kommunikations- und Sinnstiftungs-Modi wie Humor, Spiel und Ritual. ${ }^{26}$ Sein nicht zuletzt durch seine Teilnahme an den Macy-Konferenzen kybernetisch inspirierter Ansatz stiftete gleichermaßen Verbindungen zwischen Mensch und Tier wie zwischen Mensch und Maschine. ${ }^{27}$

24 Die einzigen Monographien zu Bateson im deutschsprachigen Raum stammen von Wolfram Lutterer: Gregory Bateson. Eine Einführung in sein Denken, vgl. ders., Auf den Spuren ökologischen Bewußtseins. Eine Analyse des Gesamtwerks von Gregory Bateson, im folgenden abgekürzt als Spuren; vgl. ferner die umfangreiche Biographie von David Lipset, Gregory Bateson, The Legacy of a Scientist.

25 Eine der wichtigsten Schriften in diesem Kontext bildet Watzlawick/Beavin/Jackson, Menschliche Kommunikation. Formen, Störungen, Paradoxien. (Englische Originalausgabe: Pragmatics of Human Communication. A Study of Interactional Patterns, Pathologies, and Paradoxes, 1967). Für eine umfassendere Kontextualisierung im Rahmen alternativer, insbesondere französischer Ansätze vgl. ferner das sehr eigenständige Werk von Anthony Wilden, System and Structure. Vgl. Gregory Bateson, Ökologie des Geistes.

27 Vgl zu den Macy-Konferenzen, deren Einschätzung sowie den Protokollen, in denen auch Batesons Teilnahme dokumentiert ist: Claus Pias, Cybernetics - Kybernetik, Bd 1 und 2; vgl. ferner Laurence Bale, Gregory Bateson, Cybernetics, and the social/behavioural Sciences, Max Visser, Gregory Ba- 
Ausgehend von Beobachtungen der Kommunikation unter Säugetieren entwirft Bateson eine Art ,Genealogie‘ der menschlichen Kommunikation. Ihr zufolge ist jene Kommunikationsform, welche sämtlichen Säugetieren zur Verfügung steht und als die für Tier wie Mensch gleichermaßen geno- und phänotypisch erste gelten kann, die expressive oder ostensive (zeigende) Beziehungskommunikation: jene Form, die Bateson die „ana$\log e^{\text {“ }}$ Kommunikation nennt. ${ }^{28}$ Sie ist von vergleichsweise großer Direktheit: ein Akt oder Zeichen bedeutet das, was es ist. Der Code ist die Message. Kämpfen beispielsweise bedeutet Kämpfen, ist also einerseits Ausdruck eines aktiven Beziehungsprozesses und damit eine Botschaft, zugleich aber ist es vor allem ein physiologischer Prozeß mit kausal-materialen wie symbolischen Folgen. Zwischen Zeichen und Bedeutung ist hier nicht zu trennen, dennoch ist beides gegeben. Ein weiteres Beispiel sind Geruchssignale. ${ }^{29} \mathrm{Sie}$ sind der äußerlich wahrnehmbare Teil eines physiologischen Prozesses: Düfte bedeuten nicht nur diesen Prozeß, im Sinne von: sie zeigen ihn an, vielmehr sind sie eine Verkörperung dieses Prozesses - so das sich auf den Rücken Werfen eines unterlegenen Hundes. Kapitulation bedeutet aber auch Kapitulation ist.

Nun sahen wir bereits, daß analoge Symbolisierung nur positive Werte hat. ${ }^{30}$ Dasselbe gilt logischerweise für Analog-Kommunikation, es bedeutet, daß hier keine Negation, kein ,nein“ und kein ,nicht“ symbolisiert werden können. (Der Tanz der Biene etwa, der sich mit Anthony Wilden auffassen läßt als eine komplexe Form analoger Codierung, sagt etwas über die räumliche Relation der Biene zur Nahrungsquelle, aber sie kann nicht sagen: „there is no food here“. ${ }^{31}$ ) Um also in analoger, non-verbaler, expressiver, auf Handlungen statt Worte angewiesener Form eine Negation zu kommunizieren, muß man das, was man nicht zu tun mitteilt, tun. Will ein Delphin seinem menschlichen Partner mitteilen „,ich werde Dich nicht beißen“, muß er - vorsichtig - beißen. Bateson schlägt unter Bezugnahme auf Russells Typentheorie vor, daß es sich hier um eine Kommunikation auf mehreren Ebenen gleichzeitig handelt. Da ist einerseits die Inhaltebene (der andeutende Biß), andererseits die diese kontextualisierende Meta-Ebene (,dies ist Spiel', man könnte hinzufügen: ,dies ist Freundschaft/Zuneigung'). Entsprechendes gilt für die analoge, also gestische, agierende Mitteilung, daß man keinen Angriff plant. Um dies zu agieren, zeigen, muß man - symbolisch - angreifen.

„Das heißt, das Gegenteil der endgültigen Mitteilung [ich werde Dich nicht ... ] wird durchgespielt, um bei einer reductio ad absurdum anzugelangen, die dann als Grundlage des beiderseitigen Friedens, des hierarchischen Vorgangs oder sexueller Beziehungen dient. Viele der erstaunlichen Interaktionen von Tieren, die man als ,Spiel' bezeichnet und die

teson on Deutero-Learning and Double-Bind: A Brief Conceptual History sowie Wolfram Lutterer, Gregory Bateson. Eine Einführung in sein Denken.

28 Diese ist in der Tat „,analog“ auch im Goodman'schen Sinn: nicht nur zählen hier Nuancen und Übergänge, sondern es ist eine zeigende, exemplifizierende Kommunikation, in der dasjenige, was symbolisiert wird, an dem Symbolisierenden angetroffen, dort verkörpert wird. - Bateson kommentiert das Verhältnis zwischen der analog-digital-Unterscheidung und den logischen Typen allgemein u. a. in: „Die logische Kategorie von Lernen und Kommunikation“, in: Bateson, Ökologie des Geistes, S. 362-399, inbes. S. 376 f. zu „Lernen I“.

29 Vgl. dazu Bateson, Ökologie des Geistes, 242

30 Vgl. oben Kapitel 5.

31 Vgl. Wilden, System and Structure, S. 167. 
dem Kampf ähneln (aber kein Kampf sind), dienen wahrscheinlich dem Überprüfen und der erneuten Versicherung einer solchen negativen Übereinkunft. Dabei handelt es sich aber um mühsame und schwerfällige Methoden, das Negativum zu erreichen. ${ }^{\text {' }}{ }^{32}$

So wird mit diesem Erreichen des Negativums als Durchgang durch die doppelte Negation (nicht negieren $=$ nicht beißen bzw. nicht angreifen) eigentlich ein Positivum zu erreichen versucht: die Etablierung von ,Frieden', ,Freundschaft' (welche man ja als sekundäre Zustände interpretieren kann: als die verhinderte Möglichkeit von Krieg bzw. Feindschaft.). Wer vorübergehend mit Welpen gelebt hat, kennt folgendes Phänomen: der Welpe liebt es, zur Aufnahme oder Intensivierung der Beziehung seine nadelspitzen Zähne in die Hand oder den nackten Arm des Menschen zu schlagen, aber nur so vorsichtig, daß es nie verletzen würde, obwohl er es leicht könnte. Versucht man, den Inhalt hinter dieser vom Welpen präzis geführten Interaktion herauszufiltern, so drückt dieses Spiel etwas aus zwischen Vertrauen, Provokation und Humor, es ist immer eine Aufforderung damit verknüpft, und es ist in jedem Fall der Entwurf bzw. das Anbieten einer intimen Beziehung, im Sinne des ,Ich könnte Dich verletzen, beiße Dich aber nicht, das heißt, wir sind Freunde“. Vor allem beinhaltet sie die Aufforderung, symmetrisch ,zurückzuspielen“, also den Beziehungsvorschlag aufzunehmen und zu festigen (etwa - da man schlecht beißen kann - indem man spielerisch den Hund in die Flanke greift und dabei knurrt).

„[Spiel] ist eine Situation, die deutlich das Auftreten von Metamitteilungen veranschaulicht, deren richtige Unterscheidung für das Zusammenwirken der beteiligten Individuen von entscheidender Bedeutung ist; so kann zum Beispiel eine falsche Unterscheidung leicht zum Kampf führen. “33

Diese Beobachtung, daß der spielerische Biß Anderes bedeutet als ein gewöhnlicher Biß, gibt in der Tat Anlaß zu aufschlußreichen Überlegungen. Deren zentrale ist der Vorschlag Batesons (der nicht Welpen, sondern Affen, Ottern, Oktopusse und Delphine beobachtete), daß der spielerische Biß (,nip “) den entscheidenden Schritt im Übergang von analoger zu digitaler Kommunikation darstellt - und damit auch von ikonischen Zeichen zu arbiträren. Dies gilt ihm zufolge, weil er das genealogisch, onto- und phylogenetisch erste identifizierbare Zeichen ist, welches etwas kommuniziert, was es zugleich auch nicht ist!

„Das spielerische Zwicken bezeichnet den Biß, aber es bezeichnet nicht, was durch den Biß bezeichnet würde". 34

Es bezeichnet nicht einen realen Kampf, einen realen Macht- oder Vernichtungsanspruch, es beinhaltet eine Kontextualisierung, im Sinne des: „Diese Handlungen, in die wir jetzt verwickelt sind, bezeichnen nicht, was jene Handlungen, die sie bezeichnen, bezeichnen

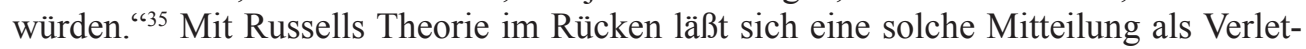
zung der logischen Typenlehre interpretieren, insofern das Wort „bezeichnen“ in zwei

\footnotetext{
32 Bateson, Ökologie des Geistes, S. 547, Hvh. S. M.

33 Bateson, Ökologie des Geistes, S. 296.

34 Bateson, Ökologie des Geistes, S. 244

35 Ebd., Hvh. S. M.
} 
Abstraktionsgraden auftritt, welche als synonym behandelt werden.$^{36}$ Das heißt, wir finden in diesem Phänomen des tierischen Spiels einen Bruch (Aufhebung) der Diskontinuität unter logischen Typen (abstrakter formuliert: einen Kategorienfehler). Und in der Tat zählen Spiel und Humor bei Bateson zu den zentralen Beispielen menschlicher wie tierischer Kreativität. ${ }^{37}$ Anders als für Russell folgt für Bateson also keineswegs das Verbot einer Überschreitung der Grenze unter involvierten Abstraktionsebenen. Im Gegenteil, er macht diese Grenzüberschreitung Zeit seines Lebens zum Gegenstand immer neuer „Modelle“ für Kognition, Lernen, Wachstum, Kreativität auf der menschlichen, tierischen und auch der rein biologisch-evolutionären Ebene. Die näheren Details seinesModells werden unten dargelegt. ${ }^{38}$ Zunächst einmal leiten er und in seinem Gefolge auch Watzlawick/Beavin/Jackson aus dieser Denkfigur ab, daß tierisches und vor allem auch menschliches Verhalten nicht nur immer wieder solche Brüche der Diskontinuität zwischen logischen Ebenen aufweist, sondern daß diese Grenzübertritte charakteristisch sind für eine Fülle produktiver kultureller Verhaltensweisen. ${ }^{39}$ In dieser Art Grenz-Überschreitung in Form des ,Spiels“ - der „nip“" als Schritt hin zu einem Zeichen, das nicht mehr schlicht bedeutet, was es ist - liegt die Basis des Übergangs von der reinen tierischen Analog-Kommunikation zur menschlichen Analog- plus Digital-Kommunikation. Wie sieht dies näher aus?

Spiel, mit seinem Moment des „als-ob“, des „dies ist nicht das, was es zu sein vorgibt", wird in der metakommunikativen Betrachtung deswegen als zentraler Schritt in der Entwicklung der menschlichen Symbolisationsformen angesehen, ${ }^{40}$ weil es einerseits wie beschrieben den Weg bahnt hin zu Zeichen, deren Bedeutung sich von dem, was sie sind, lösen. Vielleicht ist dies mit ein Grund, warum Kinder in ihrem mehr als eineinhalb Jahrzehnte währenden Übergang hin zum Erwachsenen nichts so leidenschaftlich und facettenreich entfalten wie das Spielen. Mit diesem tierisch-spielerischen „nicht“ des nips ist die erste Stufe auf dem Weg hin zu arbiträren Zeichen erreicht: ein Schritt von enormer Reichweite innerhalb der Kommunikationsentwicklung.

Andererseits beinhaltet Spiel die Anwesenheit mehrerer Sinn-Ebenen gleichzeitig, mit deren Koinzidenz in realen Kommunikationsabläufen oft virtuos jongliert wird - sodaß ein Handeln jederzeit als Probehandeln (Schein) dementierbar ist und dennoch die Beteiligten wissen, daß eine bestimmte Dimension an Ernst des Spiels in jedem Fall nicht zurückzunehmen ist. (Und sei es etwa die des Kräftemessens und Rang-Austestens.) ${ }^{41}$

36 Ebd.: ,nach der logischen Typenlehre ist eine solche Mitteilung natürlich unstatthaft“".

37 Vgl. dazu auch unten, insbes. Kap. 6.3.

38 Vgl. unten Kap. 6.5. zur „Denkspirale“.

39 Vgl. hierzu unten Abschnitt 6.4. und 6.5.

40 Bateson, Ökologie des Geistes, S. 245, 251.

41 Damit wäre die „Infanthood“ beim Menschen die Entwicklungsstufe des höchsten Erfindungsreichtums. Kinder erfinden und lernen als Lieblingsbeschäftigung neue Spiele, was hiernach konkret heißt: sie erfinden ständig neue Beziehungen zwischen Einzelhandlung und deren Kontext, Rahmung. Was ist am Phänomen des Spiels so interessant? Warum auch leben Kinder auf bei Scherzen: wenn die Erwachsenen sich plötzlich so verhalten, daß man eine Bemerkung als Spiel auffassen kann? Es ist das sich Öffnen von Türen, die Möglichkeit neuer Regel-Welten, das exploratorische Erkunden von Grenzen. ,Das ist Spiel` eröffnet in der Tat schlagartig eine neue Ebene, die alte besteht aber weiter, sodaß die neue Ebene eine neue Information über das Alte gibt: eine Lust-steigern- 
Das Spiel führt also die Dimension der Negation in die Ursprungs-Domäne des Analogen ein. Dabei kommuniziert es generell zwei Arten des ,Nein“ oder des „Nicht“: a) die im Spiel ausgetauschten Mitteilungen oder Signale sind in gewissem Sinne unwahr oder nicht gemeint, vielmehr gilt ihr Gegenteil (wie beim rituellen Schein-Angriff zu Freundschaftszwecken), und b) das, was mit diesen Signalen symbolisiert ist, existiert nicht. ${ }^{42}$ ,Dies ist Spiel' besagt eine Negation der gewöhnlichen Realität, es heißt gewissermaßen: , dies findet in einem anderen logischen Rahmen oder in einem anderen Realitätsfeld statt'. Wer ein Spiel erfindet, entdeckt eine neue Mechanik/Gesetzlichkeit ,hinter ' den Erscheinungen: schafft gewissermaßen neue Generalisierungen über Einzelfälle. (Kinder tun dies ununterbrochen, und verstärkt dann, wenn neue, unbekannte Spielgefährten auftauchen: es ergibt sich ein Austausch neuer Spielregeln und damit alternativer Meta-Ebenen: es ist wie ein neuer ,Regel-Gen-Pool', der hier ausgetestet wird: auf seine Fruchtbarkeit alias Anschließbarkeit hin). ${ }^{43}$

Neue Spielregeln sind nun evidenterweise eine Form des ,Kommunizierens über Kommunizieren“", Spielregeln sind Meta-Regeln und damit von einem höheren logischen Typ als Spielhandlungen (sie sind ,über“ diese), vor allem aber ist die Markierung von etwas als „Spiel“ ein erster vermittelnder Schritt zwischen Handlung und einer von dieser abgelösten ,Bedeutung ‘ - mithin ein Schritt hin auf dem Weg zu arbiträren Zeichen. Beschreiben kann man diesen entscheidenden Sprach- und Denk-evolutionären Schritt als die Integration von etwas, das Alfred Korzybski die „,map-territory-Relation“ nennt (,,The map is not the territory.“). ${ }^{44}$ Sprache ist „über“ Welt, wie Regeln ,über“ Handlungen sind oder die Bezeichnung von sets, Klassen, eine Information ,über“ ihre Mitglieder. Die Möglichkeit, zwischen Karte und Territorium zu unterscheiden ist Produkt der Sprache und der Codes, und Spiel ist das (logische und wohl auch genealogische, phylogenetische

de Erfahrung. (Vgl. Bateson, Geist und Natur, S. 90: die Schnittmenge AB gibt Information neuen Typs über A)

42 Vgl. auch Bateson, Ökologie des Geistes, S. 247 f.

43 Sich untereinander im-Moment-erfundene Geschichten-Erzählen in der Kindheit: ist das angestrebte Ziel in diesem Phantasieren nicht Expertise in (subversiven) Meta-Regeln?

44 Alfred Korzybski prägte diesen Satz 1931 in seinem Vortrag „A Non-Aristotelian System and its Necessity for Rigour in Mathematics and Physics“, präsentiert vor der American Mathematical Society des Meeting der American Association for the Advancement of Science (wieder abgedruckt in ders., Science and Sanity, An Introduction to Non-Aristotelian Systems and General Semantics, S. 747-761). Vgl. zu Korzybskis Diktum etwa Bateson/Bateson, Wo Engel zögern, Kap. XV, S. 214-220. - Als treffende philosophische Beschreibung eines solchen Mißverständnisses bzw. einer dergestalten professionellen Konfusion zwischen Karte und Territorium vgl. Nelson Goodman: „Philosophers sometimes mistake features of discourse with features of the subject of discourse. We seldom conclude that the world consists of words just because a true description of it does, but we sometimes suppose that the structure of the world is the same as the structure of the description. This tendency may even reach the point of linguomorphism when we conceive the world as comprised of atomic objects corresponding to atomic sentences. A reductio at absurdum blossoms when an occasional philosopher maintains that a simple description can be appropriate only if the world is simple; or asserts (and I have heard this said in all seriousness) that a coherent description will be a distortion unless the world happens to be coherent. According to this line of thinking, I suppose that before describing the world in English we ought to determine whether it is written in English, and that we ought to examine very carefully how the world is spelled." In: Nelson Goodman, Problems and Projects, S. 24. 
und ontogenetische) Zwischenstadium auf dem Weg zu dieser Entwicklung. Hier liegt vielleicht die wichtigste ,Spiel'-theoretische Beobachtung Batesons, und man lasse sich nicht dadurch irritieren, daß er für ,analog“ und „,digital“ die Freud'schen Ausdrücke „Primärprozeß“ (Medium Bild) und „Sekundärprozeß“ (Medium Sprache) verwendet, wenn er festhält, daß

„Spiel in der Entwicklung der Kommunikation den einen Schritt nach vorne bedeutet - den entscheidenden Schritt in der Entdeckung von Karte-Territorium-Relationen. Im Primärprozeß werden Karte und Territorium gleichgesetzt; im Sekundärprozeß können sie unterschieden werden. Im Spiel werden sie sowohl gleichgesetzt als auch unterschieden." ${ }^{45}$

Folgende Hierarchien von Verhaltensformen können also unterschieden werden. Erstens gibt es die gerade beschriebene Ebene, in der Handlungsformen oder auch Geschehnisse auftreten als das, was sie sind: etwa im realen Kampf. Zweitens entwickelt sich - als kulturelle Leistung - von hier aus jene Ebene, in der die Handlungen zugleich sind was sie sind und dies nicht sind, etwa beim Ritual, beim rituellen Angriff, Spiel etc. Um derlei angemessen zu interpretieren, muß man zugleich inner- und außerhalb des Rahmens sein, das heißt auf einer perspektivisch „höheren“ oder „weiteren“ Beobachtungsstufe, die beide umfaßt. Und in der Tat ist diese Gleichzeitigkeit immer dann erreicht, wenn wir versucht sind, uns über eine Situation bzw. Handlung zu verständigen. („War das Ernst?“ „Machen Sie Witze?“ „Sollte das ironisch sein?“ „Ist das eine verhüllte Drohung?") „Spiel“ kann man als primären Fall von „Kommunikation über Kommunikation“ auffassen: in diesem Sinne als den basalen Akt von „logical typing“. Die dritte Kommunikationsebene schließlich ist die der Sprache, Codes, Notationen, in der Zeichen überwiegend arbiträr sind.

Auf der Basis dieser Analyse nun stellt Bateson diverse Beispiele kulturellen und kognitiven Verhaltens vor, die die These der notwendigen Diskontinuitätsaufhebung (also des kalkulierten Kategorienfehlers) zwischen logischen Ebenen veranschaulichen. Zunächst werden im Folgenden die hierauf gründenden Kommunikations-Pathologien thematisiert (6.3), dabei geht es auch um Begrifflichkeiten zum „Double-Bind“ und zur Schizophrenie-Analyse. Anschließend (6.4) geht es um die damit eng verbundenen produktiven Formen der kulturellen Evolution, insbesondere die Lerntheorie. In Abschnitt 6.5 wird versucht, das in Batesons Werk implizit steckende evolutionstheoretische Kreativitätsmodell zu rekonstruieren. Schließlich wird auf dessen Basis in Kap. 6.6 ein eigenes Modell zur Theorie der schöpferischen Prozesse vorgeschlagen.

45 Bateson, Ökologie des Geistes, S. 251, Hvh. S. M. 


\title{
6.3 Pathologie und Produktivität: Entfaltung und inszenierter Bruch der Diskontinuität logischer Hierarchien
}

\begin{abstract}
Wir glauben, daß Paradoxien der Abstraktion in jeglicher Kommunikation auftauchen müssen, die komplexer ist als die der Stimmungs-Signale, und daß die Entwicklung der Kommunikation ohne diese Paradoxien am Ende wäre. Das Leben wäre ein endloser Austausch von stilisierten Mitteilungen, ein Spiel mit strengen Regeln, ohne Entlastung durch Veränderung oder Humor.
\end{abstract}

Gregory Bateson

Der Import der Russell'schen Typentheorie in sozialwissenschaftliche und philosophische Bereiche seitens Batesons Forschergruppen erregte zunächst über die Schizophrenie-Analyse Aufmerksamkeit. ${ }^{46}$ Es stand damit ein Beispiel entgleisender Kommunikation im Vordergrund; ein Blick auf die im selben Zeitraum und Arbeitszusammenhang entstandenen Texte zeigt jedoch, daß die pathologischen (Schizophrenie) und die produktiven (Spiel, Humor, Ritual, Kreativität) Konsequenzen der beobachteten Diskontinuitätsaufhebung (also hergestellten Kontinuität) zwischen logischen Ebenen letztlich denselben Prozeß beschreiben. ${ }^{47}$ Die altbekannte Nähe zwischen Produktivität und Wahn(-sinn) findet sich unter dem typentheoretischen Blick in neuer Version. Bateson und seine Kollegen untersuchen das Verhältnis unterschiedlicher Mitteilungsebenen zueinander: der Inhalts- oder Handlungsebene(n) einerseits und der ihren Kontext festlegenden Meta-Ebene(n) andererseits. Sie analysieren sie analog zum Verhältnis von Element und dessen Klasse (also einer Aussage oder einem Akt und einer verbalen oder nonverbalen Metakommunikation wie „Dies ist Spiel“ oder „Dies ist eine Drohung“"). Das Ergebnis:

,[W]ährend ... in der formalen Logik der Versuch unternommen wird, diese Diskontinuität zwischen einer Klasse und ihren Elementen zu erhalten, ... [wird] diese Diskontinuität in der Psychologie realer Kommunikationsabläufe kontinuierlich und unausweichlich durchbrochen." ${ }^{* 48}$

Letzteres geschieht ihnen zufolge einerseits in den unten näher analysierten produktiven Verhaltensformen von Humor, Phantasie, Ritus etc., vor allem aber in pathologischen Fällen. In diesen müssen wir ,a priori mit dem Auftreten einer Krankheit im menschli-

46 Der zentrale Aufsatz „Toward a Theory of Schizophrenia“ (1956; wieder abgedruckt in Bateson, Ökologie des Geistes, S. 270-301) ist eine Gemeinschaftsproduktion von Gregory Bateson, Don D. Jackson, Jay Haley und John H. Weakland: Produkt eines zweijährigen Forschungsprojekts des Department of Sociology and Anthropology der Stanford University. Es war Batesons Schüler und Mitarbeiter, der spätere Familientherapeut Jay Haley, der offenbar als erster die Russellsche Typentheorie auf kognitive Störungen wie Schizophrenie übertrug (vgl. dort Fußnote 1) und damit die Basis für die verzweigten Implikationen der ganzen Bateson'schen Theorie legte. Bateson betrachtet die Kommunikationstheorie als Ausweitung der Informationstheorie um die analoge Seite; vgl. Ökologie des Geistes, S. $376 \mathrm{f}$.

$47 \mathrm{Zu}$ den für das folgende zentralen Texten gehört neben dem genannten Schizophrenie-Aufsatz v. a. „A theory of play and fantasy“ („Eine Theorie des Spiels und der Phantasie“), ebenfalls abgedruckt in Ökologie des Geistes, S. 241-261.

48

Bateson, Ökologie des Geistes, S. 271. 
chen Organismus rechnen ..., wenn gewisse formale Muster dieser Durchbrechung [breaching] in der Kommunikation zwischen Mutter und Kind auftreten." ${ }^{\text {"49 }}$

In diesem Bruch der Diskontinuität liegt, so die These, die Basis des Verhaltensphänomens der Schizophrenie. Zur Veranschaulichung der Ätiologie dieser Störung beschreiben die Autoren eine Kommunikationsform von Mutter und Sohn, in der die (primäre) Kommunikations- oder Inhaltsebene mit der (sekundären) Meta- oder Beziehungs-Ebene kollidiert. $^{50}$

„Ein junger Mann, der sich von einem akuten schizophrenen Schub leidlich gut erholt hatte, wurde im Krankenhaus von seiner Mutter besucht. Er freute sich über ihr Kommen und legte ihr impulsiv seinen Arm um die Schultern, worauf sie erstarrte. Er zog seinen Arm zurück, und sie fragte: ,Liebst du mich nicht mehr?' Daraufhin wurde er rot, und sie sagte: ,Lieber, du darfst nicht so leicht verlegen werden und Angst vor Deinen Gefühlen bekommen.' Der Patient war danach nicht in der Lage, länger als ein paar Minuten mit ihr zusammenzusein, und nachdem sie gegangen war, griff er einen Assistenten an und wurde ins Bad gesteckt. “51

Das Forscherteam identifiziert in derlei Interaktionsmustern einen Double-Bind, den es als charakteristisch für Interaktionsstrukturen in jenen Familien ansieht, in denen schizophrenes Verhalten entsteht. Die Pointe dieser Situation liegt darin, daß der Konflikt nicht unter Situationen auf derselben Ebene statthat (wie anders der Fall etwa beim Kierkegaard'sche Diktum ,heirate, du wirst es bereuen, heirate nicht, du wirst es bereuen, heirate oder heirate nicht, du wirst beides bereuen'), sondern zwischen zwei unterschiedlichen logischen Typen: der Inhalts- und Meta-(Beziehungs-)Ebene. ${ }^{52}$ Die konfligierenden Signale führen zu einer besonderen no-win-situation ${ }^{53}$ : Egal, was man hier tut, man wird „bestraft“. Doch der Widerspruch ist logisch eben genau darum nicht zu formulieren, weil die beteiligten Komponenten nicht direkt aufeinanderprallen, sondern - als auf unterschiedlichen Ebenen bestehend - gleichsam wie in einer Möbius-Schleife immer wieder ineinanderfallen, ohne einander zu begegnen und ohne daher als widersprüchlich erkannt zu werden.

49 Bateson, Ökologie des Geistes, S. 271, Ergänzung S. M.

50 Die Begriffe „primär“ und „sekundär“ entsprechen hier nicht dem Primär- und Sekundärprozeß im Freud'schen Sinn, sondern bezeichnen in gewisser Weise jeweils das Umgekehrte. Dies birgt insofern das Potential für Verwirrungen, als Bateson sich andernorts wiederum genau besagter Freud'scher Terminologie für dieses Ebenen-Problem bedient; vgl. dazu die folgenden Unterkapitel.

51 Ebda 289. - Diese, wie andere prominente Stellen aus Batesons Ökologie des Geistes finden sich wörtlich zitiert in Watzlawick/Beavin/Jackson, Menschliche Kommunikation: ein Buch, das aus dem Bateson-Umkreis des Mental Research Institute Palo Alto hervorging. Zu den zum Teil bedeutsamen Differenzen zwischen den beteiligten Autoren vgl. Lutterer, Spuren, S. 107-109.

Beispiel: „Bei dem, was bei ihr zu Identifikation von Mitteilungen führt, widerspricht sie ständig. Sie lacht, wenn sie sagt, was für sie am wenigsten lustig ist, und so weiter. ... [Die Konsequenz ist, daß] das Ich zwischen Tatsache und Phantasie, zwischen Buchstäblichem und Metaphorischem nicht mehr zu unterscheiden vermag“. Bateson, Ökologie des Geistes, S. 268

53 „Das unmögliche Dilemma lautet also: ,Wenn ich meine Bindung an Mutter behalten will, darf ich ihr nicht zeigen, daß ich sie liebe, aber wenn ich ihr nicht zeige, daß ich sie liebe, werde ich sie verlieren." "Bateson, Ökologie des Geistes, S. 291. (Alternative: Wenn Du geliebt werden willst, darfst Du nicht zeigen, daß Du selbst liebst. $=$ Du wirst nur geliebt, wenn Du selbst nicht liebst.) 
Generell stellen die Autoren eine Liste von Ingredienzen auf, welche gemeinsam zu besagter ,double-bind“-Situation mit pathologischem Resultat führen. Diese beinhaltet

1.) zwei oder mehr beteiligte Personen (den Adressaten/Opfer und die Bezugsperson/ Familie)

2.) eine nicht einmalige, sondern wiederholte Erfahrung, die sich zu habitueller Erwartung verdichten kann,

3.) ein primäres Gebot negativer Art (wenn Du so [nicht] handelst, werde ich Dich bestrafen/verlassen),

4.) ein sekundäres Gebot, das mit dem ersten in Widerspruch bzw. Konflikt steht und ebenfalls durch Strafen oder Signale verstärkt wird, die das Überleben bedrohen wobei dieses sekundäre Gebot in einer anderen „Sprache“ und auf einer anderen Ebene kommuniziert wird als das erste,

5.) ein ternäres Gebot, das es verbietet, den Schauplatz des Konflikts zu fliehen.

Da sich das primäre und das sekundäre Gebot auf zwei verschiedenen Abstraktions- und Kommunikationsebenen befinden, läßt sich der Widerspruch nicht auflösen. Die beiden Abstraktionsebenen zeigen sich wesentlich darin, daß sekundäre Gebote wie im obigen Beispiel (,sie erstarrte“) nonverbal, d. h. über Verhalten, Ausdruck, Körper, Tonfall, Anspielungen vermittelt werden - und im übrigen von den Akteuren in der Regel un-intendiert ausgesendet und von den Rezipienten unbewußt wahrgenommen werden. Das sekundäre Gebot ist ,, über “ das primäre Gebot, d. h. es rahmt, kategorialisiert oder kontextualisiert es und setzt es zugleich außer Kraft. Es erstellt ein Paradox. Nicht selten gehen das primäre und das sekundäre Gebot auch von unterschiedlichen Personen innerhalb desselben (Familien-)Systems aus.

Charakteristisch ist nun, daß die Autoren nicht nur besagtes zweites Gebot mittels der Russell'schen Typentheorie analysieren, sondern im selben theoretischen Atemzug sämtliche klassifizierende Kontext-modifizierende Signale, zu denen auch Elemente des menschlichen und tierischen Spiels, der Phantasie, Ritus, Metapher, Kunst u. a., gehören. Sie alle sind generell

„von einem höheren logischen Typ als die Mitteilungen, die sie klassifizieren. Bei menschlichen Wesen erreicht diese Rahmung und Etikettierung [framing and labelling] von Mitteilungen und bedeutungsvollen Handlungen eine beträchtliche Komplexität, allerdings mit der Besonderheit, daß unser Vokabular für solche Unterscheidungen noch sehr spärlich entwickelt ist, und wir uns überwiegend auf nonverbale Ausdrucksmittel der Körperhaltung, der Gestik, des Gesichtsausdrucks, des Tonfalls und auf den Kontext für die Kommunikation dieser hochabstrakten, aber lebenswichtigen Etikettierungen verlassen müssen." ${ }^{\text {"54 }}$

Je höher der logische Typ, so ließe sich verallgemeinern, desto schwieriger ist sein Inhalt in Worten zu identifizieren. Auch wenn Sätze wie „dies ist nur Spaß“ oder „,es tut mir leid“ oder „,ich liebe Dich“ mehr oder weniger leicht über die Lippen gehen - sie sind alleine nicht aussagekräftig. Und in realen lebenspraktischen Kommunikationsabläufen beobachten wir die nonverbalen Anzeichen zur Identifizierung von Meta- bzw. Beziehungsebenen eben deshalb so genau, weil ihr Inhalt entweder nicht präzise und feinkörnig

54 Bateson, Ökologie des Geistes, S. 272 
artikulierbar ist oder - ebenfalls häufig - nicht in Worte gefaßt werden soll. Oft existiert ein gesellschaftliches Tabu der direkten Artikulation dieser nonverbalen Beziehungs-Inhalte, selbst wenn sie allen Beteiligten bewußt sind und sein sollen. ${ }^{55}$

Das Neue dieser Analyse gegenüber älteren der, Gleichzeitigkeit des Unterschiedlichen ${ }^{65}$ ist wie betont, da $\beta$ die infragestehende kognitive Kollision nicht nur eine von Inhalten, sondern zugleich von Ebenen ist, das heißt auch, nicht nur von logischen, sondern auch ontologischen ,Typen“. Die „Elemente“ sind Einzelfälle von Handlungen (in dem Beispiel etwa das Umarmen, das Zurückziehen und Erröten), der „Set“ sind die, hier emotiven, Klassifizierungen dieser Handlungen (Verlegen-werden, eigene Gefühlen fürchten). Deutlich ist, daß die Mutter die Einzelhandlungen des Sohnes (Elemente) zu generellen Verhaltensdeutungen für ganze Klassen oder Sets von zukünftigen Handlungen umdeutet. Dies stellt evidenterweise einen Akt der Gewalt und Willkür dar, weil eine Einzelhandlung nie zugleich ihre Klasse mitliefert, d. h. jeweils diverse Generalisierungen (Typisierungen) erlaubt. In eben diesem Punkt ist die Analyse Batesons noch zu ergänzen: die Kollision der logischen Ebenen äußert sich in einer Umdeutung - von der Einzelhandlung zu ihrer Kategorialisierung. Man kennt dies aus vielen Familienkonflikten: aus einem Tun wird oft umstandslos die Charakterisierung des ganzen Charakters bzw. einer ganzen Einstellung abgeleitet. (,Immer mußt Du ...!")

Ferner: die Kollision arbeitet mit einem komplexen Ineinander von verbalen und nonverbalen/expressiven Mitteilungen. So sind in diesem Beispiel sowohl die Einzelhandlungen (Umarmen, Rückzug, Erröten, „liebst Du mich nicht mehr?“) als auch die Klassifizierungen beides: zugleich sagend/verbal und zeigend/expressiv. In anderen Worten, das Individuum gerät in eine Situation, in der es von Vorteil ist, die Kommunikation bzw. ihre Meta-Ebenen nicht genau zu interpretieren, will es sich bzw. die Beziehung nicht gefährden. ${ }^{57}$ Das Individuum lernt, seine Fähigkeit, zwischen logischen Typen zu unterscheiden, aufzugeben. ${ }^{58}$ - Das Resultat solcher Interaktionen ist logischerweise im Extremfall eine schwere kognitive, Verstimmung' (von der emotionellen ganz zu schweigen). ${ }^{59}$

55 Ein Beispiel: Im ländlichen Ungarn existiert angeblich der Brauch, daß der junge Mann, der bei der Familie um die Hand seiner Erwählten anhält, in die gute Stube geführt wird und seinen Hut dort auf das Bett legt. Wenn der Hut dort beim Weggehen noch liegt und nicht weggeräumt wurde, ist der Bräutigam akzeptiert. Man kann die Abweisung nicht direkt ausdrücken, ohne das Gegenüber zu entehren. - Vgl. auch Coaching-Regeln für Bewerbungen: ,Achte auf unbewußte Doppelsignale: Wenn du schüchtern bist und das zu verbergen suchst, kommt als nonverbale Botschaft heraus: Ich mag euch nicht! (Vgl. auch Ökologie des Geistes, S. 273: „Das Subjekt kann Schüchternheit für Mißachtung halten, etc.")

56 Diese Analyse liegt etwa der „Bisoziationstheorie“ Arthur Koestlers zugrunde, auf welcher seine Kreativitätstheorie aufbaut. Vgl. Arthur Koestler, „The Three Domains of Creativity“ sowie unten. Vgl. Ökologie des Geistes, S. 285

58 In so einem Fall gilt für den - hier - Patienten etwa folgendes: „Fragt [ihn jemand]: ,Was würden Sie heute gerne tun?‘, so wird [er] unfähig sein, aufgrund des Kontextes, des Tonfall oder der Gestik genau zu beurteilen, ob [er] wegen seines gestrigen Verhaltens gemaßregelt werden soll, ob man es zu einer sexuellen Handlung einlädt, oder was sonst gemeint ist.“ Bateson, Ökologie des Geistes, S. 281, vgl. auch S. 262.

59 Der einzige mir persönlich begegnete Fall diagnostizierter Schizophrenie (der in Selbstmord endete) ist jener des Bruders einer Schulfreundin. Dieser wurde als Kind von seinem Vater gezwungen, 
Der Gewinn einer solchen typentheoretischen Analyse liegt darin, diese spezielle pathologische Konditionierung nicht als Ver-rücktheit oder Verwirrtheit zu beschreiben, sondern als in sich folgerichtige Denkstruktur, mit System“: Es gilt in dieser Analyse der Schizophrenie, die Logik jenes Systems oder Universums zu erfassen, welche jene unkonventionellen Kommunikationsgewohnheiten angemessen oder gar überlebensnotwendig macht. ${ }^{60}$ Auch wenn diese auf der Double-Bind-Analyse basierende Schizophrenietheorie viel Kritik erfuhr und ihr noch Jahre nach Erscheinen des ersten Aufsatzes teilweise selbstkritische Ergänzungen angefügt wurden, ${ }^{61}$ hatte der Text doch ,den Effekt einer Bombe, die einen Damm von rigiden Vorstellungen zum Wesen dieser rätselhaften Affektion ins Wanken brachte und eine Flut von Publikationen zum Problem der schizophrenen Kommunikationsstörungen auslöste, die bis heute nicht verebbt ist" ".62

Die logische Verwandtschaft von Pathologie und Produktivität zeigt sich von hier aus deutlicher. Der ,Kranke“ leidet darunter, unter konkurrierenden Klassifikations- oder Set-Möglichkeiten keine positive Wahl treffen zu können, weil jede Wahl die Verletzung oder das unbotmäßige Verlassen einer von zwei logischen Ebenen bedeutete (Effekt: Gefängnis). Der ,Kreative' nutzt just diese logische Verstrickung, um mit einem Bruch ihrer eine Inhaltsebene mit neuer, veränderter Bedeutung aufzuladen (Effekt: Freiheit). Letzteres Modell zeigt sich etwa am Prinzip des Humors bzw. Witzes ${ }^{63}$, und es ist Bateson zufolge ein entscheidendes Prinzip wissenschaftlicher Entdeckungen und des Lernens generell. ${ }^{64}$ Ein Witz aus dem kreativitätstheoretischen Standardwerk des Bateson-Zeitgenossen Arthur Koestler möge dies veranschaulichen:

„A nobleman at the court of Louis XV had unexpectedly returned from a journey and, on entering his wife's boudoir, found her in the arms of a bishop. After a short hesitation, the nobleman walked calmly to the window and made blessing gestures to the people in the street. - ,What are you doing?' cried the anguished wife. ,Monseigneur is performing my functions', replied the nobleman, ,so I am performing his “"665

seine jüngeren Schwestern zu fangen, dem Vater auszuliefern und festzuhalten, sodaß letzterer sie schlagen konnte. Der Fall entspricht der Bateson'sche Beschreibung sehr genau.

60 Vgl. Bateson, Ökologie des Geistes, S. 275

61 Vgl. Lutterer, Spuren, S, 104 f., zur Veröffentlichungs- und Rezeptionsgeschichte des Aufsatzes auch ebd. S. 97-104.

62 Luc Ciompi, Affektlogik: über die Struktur der Psyche und ihre Entwicklung; ein Beitrag zur Schizophrenieforschung, S. 177.

63 Verbindungen zu Witz- bzw. Humor-Analysen Sigmund Freuds, Arthur Koestlers, Henri Bergsons, Georges Batailles u. a. müssen hier notwendigerweise vernachlässigt werden, obwohl Parallelen bestehen.

Dieser Gesichtspunkt wird von Bateson noch deutlicher in seiner späten Publikation Geist und Natur dargelegt. Vgl. hierzu auch unten, Kap. 6.4 und 6.5.

65 Arthur Koestler, „The Three Domains of Creativity“, S. 4. - Man könnte als Alternative auch folgenden Witz betrachten: Ein bayrischer Katholik liegt auf dem Sterbebett. Kommt der Priester und fragt wohlwollend, ob er noch etwas zu beichten hat. Der Sterbende windet sich, zögert lange und gesteht schließlich widerstrebend, er sei kürzlich in die SPD eingetreten. Was?, so der Geistliche, bist Du verrückt? Warum um Himmels Willen hast Du das gemacht? - Nun, antwortet der Katholik, ich dachte es ist besser, es stirbt einer von denen! 
Koestler analysiert diese Geschichte als Kollision oder, wie er sagt, „Bisoziation“ zweier wechselseitig inkompatibler Kontexte. ${ }^{66}$ Allerdings hat er kein sehr ausgearbeitetes Konzept unterschiedlicher Abstraktions-Ebenen und -Hierarchien, obwohl seine kreativitätstheoretischen Formulierungen genau auf Derartiges zielen. Der komische Effekt liegt jedoch nicht nur im Austausch vom Profanen gegen das Heilige (oder vom Obszönen gegen das Erhabene). Er läßt sich hier gerade als Aufeinanderprall unterschiedlicher logischer Klassen analysieren. Der Bischof vollzieht mit der Frau zusammen eine Einzelhandlung (die für sich selbst steht und gerade auffällig wenig symbolische Relationen zu seiner Funktion als Amtsträger aufweist). Die segnende Geste des Adligen hingegen ist gewöhnlich gerade eine Geste höheren logischen Typs (der Segen ist „über“ die Empfänger, schreibt den Empfängern einen Modus zu: ,Ihr seid gesegnet').

Batesons Analyse des Humors ist geeignet, einen solchen Fall zu illustrieren:

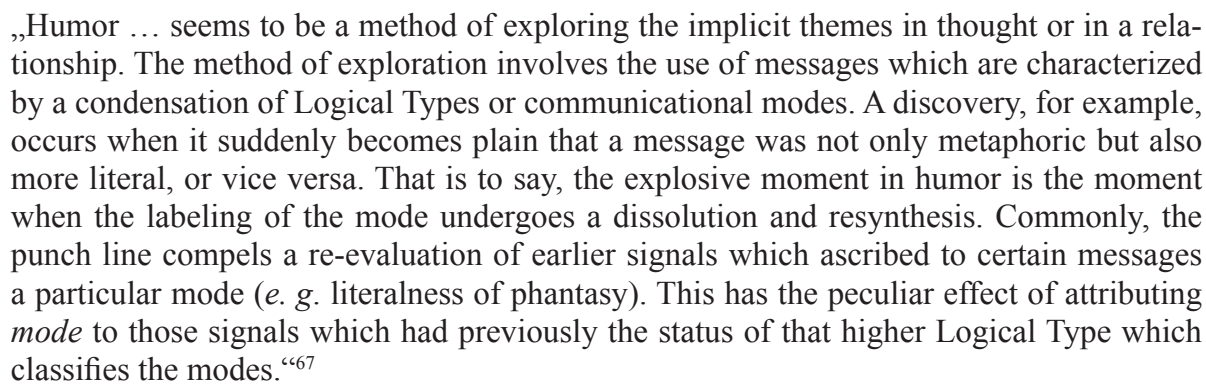

Der Koestler'sche Witz arbeitet genau mit diesen Ebenen-Re-Evaluationen. Dadurch, daß der Adlige zum Fenster geht und die Geste macht (also eine Geste, die ursprünglich gerade nicht für sich steht, sondern für ein höheres Gut: das wohltätige Wirken Gottes an den gesegneten Objekten), und dies als symmetrischen Austausch zwischen zwei „Funktionen" deklariert, werden beide Taten umgewertet, re-klassifiziert, einem neuen „mode“ unterzogen. Die sexuelle Handlung zwischen Bischof und fremder Ehefrau, die in jenem Moment in der Regel gar nichts symbolisiert und symbolisieren soll ${ }^{68}$ sondern allein für sich steht, wird durch die adlige Reaktion ex post ebenso in jenen „höheren“ Bereich rituellen Über-sich-Hinausweisens gehoben wie die segnende Geste herunterprofanisiert wird. Zugleich hat die Geste auch den umgekehrten Effekt: dergestalt, daß die Berufsausübung des Bischofs durch das gestische Zitat des profanen Adligen am Fenster rückwirkend aller „höheren“ Ebenen entkleidet wird und nichts mehr bedeutet als die nackte Armbewegung. Kurz, durch den behaupteten „Tausch“ bekommen beide Aktivitäten schlagartig einen anderen Modus: einerseits typen-hierarchisch und in diesem Sinne logisch, andererseits kollabiert der scheinbar weite und grundsätzliche Abstand von heiligen, transkörperlichen, moralisch aufgeladenen zu trivialen, körperlichen, moralfreien Handlungen. Die Kollision ist eine logische, und der komische Effekt resultiert

66 Generell finden sich zwischen Batesons hier dargelegter Theorie und Koestlers Kreativitätstheorie diverse Ähnlichkeiten, wobei vieles des Koestler'schen Gedankenguts, etwa zum Rhythmus, durch die Russell-Bateson'sche Interpretation präziser beschreibbar wäre.

67 Bateson, Steps to an Ecology of Mind, S. 203. Die deutsche Übersetzung in Ökologie des Geistes, S. 272 ist an dieser Stelle leicht irreführend.

68 Sie symbolisiert nichts, wenngleich sie auch etwas bedeutet: den beteiligten Personen. 
aus dieser typentheoretischen „Übersprungshandlung“ nicht nur vom Profanen/Obszönen zum Heiligen, sondern auch von der Einzelhandlung zur Klasse der Handlungen, die für Allgemeines stehen. So ist die Pointe in der Tat nicht nur ein Zusammenprall des Inkompatiblen, sondern Größe wie Witz der Reaktion des Adlige bestehen in seinem ,calculated category-mistake'.

Die Existenz und die Wechselrelation mehrerer logischer Ebenen gleichzeitig ist nun evidenterweise weder allein ein Merkmal von Pathologie noch von Produktivität; sondern es ist auch die alltägliche - wenngleich häufig übersehene - Situation in gewöhnlicher Selbst- und Fremdverständigung. Kein Inhalt besteht ohne kontextualisierende Rahmen, und diese Ebenen können mehr oder eben auch weniger stark übereinstimmen. ${ }^{69}$

Bateson leitet eine Kritik aus der vielfach gut verankerten Praxis von Geistes- und Naturwissenschaften im akademischen Bereich ab, beim Tradieren von (digitalem) Wissen dessen Einbettung in einen größeren, umfassenden Zusammenhang zu unterschlagen oder gar zu löschen - im Interesse wissenschaftlicher Objektivität und Abstraktion. Batesons Credo von ,pattern that connects“ lautet: „Brich das Muster auf, das die ... Wissens-Inhalte verbindet, und du zerstörst notwendigerweise alle Qualität." ${ }^{\text {"70 }}$ Anthony Wilden sekundiert: ,Ignorance of the context seems to be one of our most highly developed cultural values. "71

In anderen Worten: Inhalt ohne Kontextualisierung dieses Inhalts ist logisch nicht existent. Pragmatisch heißt es ferner: löse die Erkenntnisse aus ihrem Gesamtkontext, und sie verlieren ihre existenzielle Bedeutung - bis hin zu im Ergebnis fatalen Konsequenzen für das Gesamtsystem. Die Schlußfolgerung daraus wäre, nicht nur den individuellen Sinn jeder Aussage als abhängig vom umfassenderen Kontext zu betrachten, sondern - in einem kalkulierten Ebenen-Sprung - das Denken und Handeln jedes konkreten Individuums grundsätzlich als Teil eines umfassenderen Systems wahrzunehmen. Letzteres ist im weitesten Sinne als ,ökologisch“ zu begreifen - und es beinhaltet die kybernetische Grundidee, daß die Produkte auf der Einzelebene wiederum rekursiv auf das Gesamtsystem einwirken: in einer Form, die nie linear kausal, sondern zirkulär vonstatten geht, mit Konsequenzen, die ebenso im Kontext der Politik, Soziologie und Ästhetik wie der Biologie und Religion relevant sind. ${ }^{72}$

Insofern ist mit der Interaktion von ,analog“ und ,digital“ in Form einer ,diskontinuierlichen' Hierarchie logischer Ebenen (und deren gelegentlich kalkuliertem Bruch) zumindest potentiell eine weitreichende Epistemologie abzuleiten, die ebenso aus der Kybernetik gespeist wird wie sie diese selbst wiederum fundiert. ${ }^{73}$

69 Erving Goffmans Frame-Analysis übernimmt Batesons Rahmen-Konzept weitgehend unverändert.

70 Gregory Bateson, Geist und Natur, S. 15, Zusatz S. M.

71 Anthony Wilden, System and Structure, S. 114. - Vgl. auch ebda S. 166 f.: „In our universities ... analog knowledge - and especially the (analog) context of (digital) knowledge - is generally denied, rejected, or ignored." Vgl. dort weiter sowie S. $114 \mathrm{f}$.

72 Vgl. zu dieser, ökologischen“ Epistemologie etwa programmatisch Bateson, Ökologie des Geistes S. 591 ff. - sowie umfassender Bateson/Bateson, Wo Engel zögern. - Zur Quelle seiner Rede von „Ökologie“ (bezogen auf Ideen) bei Sir Geoffrey Vickers vgl. ebda S. 592.

73 Bateson hat dies vor allem in seiner spät und zusammen mit seiner Tochter verfaßten, posthum erschienenen Publikation Wo Engel zögern unternommen. Vgl. zu dieser Wechselwirkungs-Figur auch Peter Harries-Jones, „Revisiting Angels Fear: Recursion, Ecology and Aesthetics“ (online: 


\subsection{Kognition und Meta-Kognition: Lerntheorie, die Hierarchie der Ebenen und der logische ,Sprung ${ }^{6}$}

Es gibt eine tiefe und unbeantwortbare Frage hinsichtlich der Natur jener ,zumindest zwei 'Dinge, die zusammen den Unterschied hervorbringen, der dadurch, daß er einen Unterschied macht, zur Information wird. Eindeutig ist jedes für sich - für den Geist und für die Wahrnehmung - eine Nicht-Entität, ein Nicht-Seiendes. Nicht unterschieden vom Seienden und nicht unterschieden vom Nicht-Seienden. Ein Unerkennbares, ein Ding an sich, das Geräusch einer klatschenden Hand.

Gregory Bateson

Parallel zur Anwendung der Typentheorie auf pathologische und schöpferische Kommunikations-Phänomene wie Schizophrenie, Spiel, Ritual, Humor und Kunst ${ }^{74}$ hat Bateson mit seinen Co-Autoren eine explizite Lerntheorie vorgelegt. ${ }^{75}$ Nach einer Phase der direkten Übertragung kybernetischer Grundideen auf Formen des Erfahrungs- und Informationszuwachses haben Lern-Phänomene und generell Probleme der Wissens-Vermittlung in Batesons Oeuvre eine immer differenziertere Gestalt angenommen. Er beschreibt darin einerseits kreative Leistungen, andererseits visiert er vor allem im Spätwerk „Geist und Natur" eine direkte Parallele zwischen geistiger und biologischer Evolution an. Eben dieses Parallele wird sich als Grund- und Zielgedanke seines Lebenswerks erweisen. Was also zunächst als Theorie des Lernens und der Wissensakkumulation beginnt, wird unter dem Stichwort „ecological epistemology“ zu einer immer weitreichenderen Auffassung von der Strukturierung des Wirklichen und des Geistes. Die Lerntheorie und die ,epistemische Ontologie' hat Bateson jahrzehntelang modifiziert.

In diesem Unterabschnitt werden Grundzüge der ersteren dargestellt: unter dem Aspekt ihrer Konsequenzen für ein Konzept der Kreativität. Im nächsten Unterabschnitt wird dann der Versuch unternommen, Batesons Motive unter kreativitätstheoretischem Gesichtspunkt in eine eigenständige Synthese zu überführen.

Wie sich eben andeutete, liegt ein Grundmotiv der ,ökologischen' Erkenntnistheorie im Motiv der „Kontextualisierung“. Information kommt nie alleine vor, sie wird erst zu einer solchen in Relation zu einem Rahmen, frame, Label. Sie benötigt die Anwesenheit mindestens zweier logischer Ebenen. Genau hier liegt im Spätwerk sein Credo bezüglich der Vermittlung von Inhalten: die digitale Information ohne deren analoge Kontextualisierung bzw. Vermittlung (das „Muster, das verbindet“) führt zu sterilen und wirkungslosen Modi der Lehre und Erziehung. Doch dies greift vor.

Betrachten wir zunächst die ein Vierteljahrhundert früher artikulierte „theory of learning “. Bateson entwickelte sie wiederum aus der Typentheorie, insofern sich aus ihr die stufenförmige und paarweise Schichtung von Denk-Inhalten bzw. Denk-Kategorien er-

http://www.library.utoronto.ca/see/SEED/Vol4-1/Harries-Jones.htm, 28.5.08), sowie ders., A Recursive Vision: Ecological Understanding and Gregory Bateson.

74 Vgl. zur Kunst etwa: „Stil, Grazie und Information in der primitiven Kunst“. In: Bateson, Ökologie des Geistes, S. 182-212.

75 Auch diese Theorie entwickelte sich ursprünglich aus Studien für die USA im Rahmen der psychologischen Kriegsführung während des zweiten Weltkriegs. 
gab - mit nach oben offenem Ende. ${ }^{76}$ Hier noch einmal eine Übersicht der oben beschriebenen logischen Hierarchisierung. ${ }^{77}$ Jeweils die höhere Schicht stellt den Rahmen dar, aus dem heraus die untere Schicht ihre Kategorie oder Klassen-Zugehörigkeit bezieht. (Die folgende Visualisierung lese man von unten nach oben.)

etc.<smiles>C1CCCCC1</smiles>

plus vierter logischer Typ (Meta-Meta-Sets)

$=$ zusammen: Aussage 3 . Ordnung

Dritter logischer Typ (Meta-Sets)

$\uparrow$

plus dritter logischer Typ (Sets über Sets: Meta-Sets) = zusammen: Aussage 2. Ordnung

Zweiter logischer Typ (Sets über Individuen)

个

plus zweiter logischer Typ

= zusammen: Aussage 1. Ordnung

(Generalisierungen/Sets über Individuen)

个

erster logischer Typ (Individuen)

Illustration 1

Aus diesem Modell folgt epistemologisch: a) daß eine jede gültige Aussage in einer Paarung aus Ebenen unterschiedlicher Abstraktionsgrade besteht (einen Kontext benötigt, Teil eines Musters ist), b) daß Aussagen über eine Ebene innerhalb dieser Paarung immer nur von der höheren Stufe aus gemacht werden können, also top-down verlaufen. ${ }^{78}$

Wenden wir nun dieses hierarchische Modell auf die Idee des Lernens an: Ihr zufolge operieren Lebewesen mit Ebenen, die paarweise hierarchisch geordnet sind. Entspre-

76 Bertrand Russell schreibt in diesem Sinne in der Einleitung zu Wittgensteins Tractatus: „Diese Schwierigkeiten legen meiner Meinung nach die Möglichkeit nahe, daß jede Sprache, wie Herr Wittgenstein sagt, eine Struktur hat, über die in der Sprache selbst nichts ausgesagt werden kann, daß es aber vielleicht eine andere Sprache gibt, die von der Struktur der ersten Sprache handelt und selbst eine neue Struktur hat, und daß diese Hierarchie von Sprachen möglicherweise unbegrenzt ist.“ Bertrand Russell, „Einleitung zu Ludwig Wittgensteins Logisch-Philosophische Abhandlung“, S. 23.

77 Vgl. oben Kap. 6.1.

78 In Watzlawick/Beavin/Jackson, Menschliche Kommunikation, S. 242 heißt das, ,daß die Welt, in der wir leben, und das Bewußtsein unserer selbst und anderer einer hierarischen Ordnung zu unterstehen scheinen und daß gültige Aussagen über eine Stufe dieser Ordnung nur von der nächst höheren aus gemacht werden können“". 
chend unternimmt Bateson die folgende lerntheoretische Aufgliederung ${ }^{79}$ - sie nicht ohne gewisse Rhetorik für „Computer, Ratten und Menschen“ konstatierend, entsprechend der ,holistischen' kybernetischen Herkunft dieser Überlegungen. ${ }^{80}$

Die Erste Ebene besteht im „Lernen Null“" (,zero-learning“, Bateson) oder auch „Wissen erster Ordnung" (Watzlawick). ${ }^{81}$ Es entspricht jenem Verhalten, das weitgehend genetisch programmiert ist (oder, im Fall von Maschinen, kausal ,eingelötet ${ }^{62}$ ) und höchstens minimal durch Erfahrung bzw. Konditionierung beeinflußt wird. Formal gleicht es jenem noch-nicht-relationalen, noch nicht interpretierten/kontexualisierten Bereich der Elemente; wir können „Lernen Null“ als Basis in Form sinnlicher Wahrnehmung interpretieren (Wissen-von im Unterschied zu Wissen-über) ${ }^{83}$ "Zero-Learning“ klingt wie ein Selbstwiderspruch, in der Tat ist es insofern noch kein Lernen, als das Individuum hier noch nicht des Irrtums fähig ist, das heißt, in Reaktion auf einen Reiz keine (bewußte) Korrektur vornimmt. ${ }^{84}$

Zweite Ebene: In dem Moment, wo das System sein Verhalten in Reaktion auf etwas Begegnendes längerfristig verändert, agiert es bereits auf zwei Ebenen gleichzeitig, befindet es sich im Lernen I (wobei vermutlich sowohl im tierischen wie menschlichen Verhalten Übergangsformen existieren) ${ }^{85}$ Lernen I oder auch „Proto-Lernen“ (entsprechend „Wissen zweiter Ordnung") ist Wissenserwerb über etwas, es entspricht unserem gewöhnlichen Begriff von Lernen: wenn ein Einzelwesen zum Zeitpunkt t ${ }_{2}$ eine andere Reaktion auf ,, denselben "Reiz zeigt als zum Zeitpunkt $t_{l}$. Lernen I ist gleichsam die „durch Versuch und Irrtum gewonnene Einschränkung (,revision') der in Betracht gezogenen Wahlmöglichkeiten innerhalb einer unveränderten Menge von Alternativen“". 86 Dabei ist es, wie Bateson zufolge Lernen auf allen Ebenen, in hohem Maße „stochastisch“: verbindet also eine Zufallskomponente mit einem selektiven Prozeß. Charakteristischerweise setzt Lernen I voraus, daß das lernende Einzelwesen bestimmte Ereignisse als dieselben ,interpunktiert“ (interpretiert), also innerhalb des Erlebten Identität stiftet. Dies geschieht durch - etwa begriffliche - Klassifikation. Ein bestimmtes Ereignis wird als neuer Fall (Wiederholung) eines alten Ereignisses klassifiziert, damit „Lernen“ stattfinden kann. Diese Handlung einer Identifikation (zweier Dinge) geschieht bereits von einer höheren Ebene aus, jener Ebene nämlich, die die Klassifizierung, das Applizieren von Prädikaten ermöglicht. Hierin liegt jene oben dargestellte Paarung (Illustration 1).

79 Vgl. zu Batesons Lerntheorie ders., Ökologie des Geistes, S. 362-399, ferner Max Visser, „Gregory Bateson on Deutero-Learning and Double-Bind: A Brief Conceptual History“, sowie Watzlawick/ Beavin/Jackson, Menschliche Kommunikation, S. 244 f.

80

Bateson, Ökologie des Geistes, S. 366, vgl. S. 367.

$\mathrm{Zu}$ „Lernen Null“ vgl. Bateson, Ökologie des Geistes, S. 366-371.

Ökologie des Geistes, S. 367.

Watzlawick/Beavin/Jackson, Menschliche Kommunikation, S. 242, ersteres ist, in Russells Terminologie, „knowledge by acquaintance“.

Die Amöbe wäre hierfür vielleicht ein Beispiel: sie stößt gegen eine Wand, ändert daraufhin ihren Kurs; wenn man sie erneut in dieselbe Richtung laufen läßt, läuft sie erneut gegen die Wand und ändert nach dem Zufallsprinzip erneut die Richtung, ad infinitum.

Ebd. S. 371. 
„Die konventionelle Annahme, daß ein Kontext zumindest in einigen Fällen wiederholt werden kann, [ist der ...] Eckpfeiler der These, daß die Erforschung des Verhaltens sich nach der logischen Typenlehre richten muß. Ohne die Annahme eines wiederholbaren Kontexts (und ohne die Hypothese, daß die Abfolge der Erfahrung für den Organismus, den wir studieren, tatsächlich in dieser Weise interpunktiert ist), würde folgen, daß alles ,Lernen von einem Typ wäre, nämlich ,Lernen null' ‘“67

Logischerweise liegt, wie oben erörtert, die Funktion des überwiegenden Teils begrifflicher Ausdrucksformen darin, zu klassifizieren, d. h. identifizierende Kontexte zu schaffen (Verschiedenes als Fall des Gleichen zu markieren).

Dritte Ebene: Lernen II oder auch „Deutero-Lernen“ (entsprechend Wissen dritter Ordnung) läßt sich in der einfachsten Form als „Lernen zu lernen“ oder Meta-Lernen bezeichnen. ${ }^{88}$ Diese dritte Ebene beinhaltet erstens die pragmatische Herausbildung abkürzender Heuristiken oder generellerer Orientierungen zur Lösung einer Problemklasse von Aufgaben. Seine Fähigkeit verbessern, eine Sprache zu beherrschen ist ein Fall von Lernen I, seine Fähigkeit verbessern, Sprachen zu lernen ist ein Fall von Lernen II. So lernt, wer ein Instrument oder eine Sprache beherrscht, die nächsten gewöhnlich leichter bzw. schneller. Solches Lernen lernen geschieht zumeist durch das Erfassen einer neuen Klasse von Regeln.

Bateson und später Watzlawick/Beavin/Jackson siedeln auf dieser Ebene jedoch auch einen ganz anderen kognitive Erwerb an, nämlich den eines einheitlichen Weltbildes“" ${ }^{89}$ einer instrumentellen Lebensanschauung (oder auch einer Konditionierung für ,schizophrene" Überlebensstrategien) und generell den Gewinn von so etwas wie einer Sinndimension für das eigene Tun und Erleiden. Da die Grundlagen für diesen Rahmen bereits in die frühe Kindheit hineinreichen, sind Überzeugungen auf dieser Ebene oft nur eingeschränkt zu beinflussen..$^{90}$ Dennoch sind Änderungen, Re-Organisationen hier oft begehrt - und sie sind wiederum nur möglich von einer darüberliegenden Ebene aus. Man kann sie also nie direkt anzielen, sondern nur über Umwege, gleichsam über ,höhere" Ziele. (Wer in großen Räumen mühelos laut Sprechen lernen will, muß - Singen lernen.)

Vierte Ebene: Lernen III (Wissen vierter Ordnung) ${ }^{91}$ : Nach dem bisher Gesagten hat ein Sich-Hinbewegen auf diese vierte Ebene einige miteinander zusammenhängende Charakteristika. A) Sie ist nur unter Ausnahmebedingungen, in herausgehobenen Momenten zu erreichen (Krisen, Umbrüche, ,Erleuchtungen“, etwa durch Kunst, Therapie, Ritual oder Religion); B) die Ebene ist (wie auch teilweise die vorigen) nonverbaler Art, bzw. die Überzeugungen hier entziehen sich gewöhnlich der Sprache. Oben wurde bereits gesagt, daß je höher die Abstraktionsebene reicht, desto unbestimmter und letztlich un-

87 Ebd. S. 373.

88 Evident ist, daß Menschen und Tiere lernen (Wissen erwerben), evident ist auch, daß Menschen und Tiere lernen zu lernen, also die Ökonomie und Geschwindigkeit des Erfahrungs-Erwerbs steigern. In der Literatur wird diese Stufe auch als Deutero-Lernen (Bateson), Set-Lernen, Lernen lernen oder Lerntransfer bezeichnet, vgl. Bateson Ökologie des Geistes, S. 378, vgl. zu weiterer Literatur auch Watzlawick/Beavin/Jackson, Menschliche Kommunikation, S. 244 f.

89 Vgl. Watzlawick/Beavin/Jackson Menschliche Kommunikation, S. 243.

90 Bateson Ökologie des Geistes, S. 389.

91 Ebd. S. 389 ff. 
genügender die Semantik der Ausdrücke wird eben daher bedarf ihre Beeinflussung nicht der Worte, sondern indirekter Wege des Agierens: durch ggf. Hindernisse wie Paradoxa hindurch: entsprechend etwa der Praxis des Zen-Buddhismus. C) Da sie eine Herausforderung/Änderung grundlegender Steuerungs- und Orientierungsmuster der umfassenden ,Persönlichkeits'-Organisation sind, ist jeglicher Eingriff hier eine sensible Angelegenheit, ,gefährlich“ (ein dramatisierendes Stichwort hierzu wäre: „Vernichtung des Selbst"). Damit zusammenhängend D): Es ist die Ebene mit der größten Chance einschneidender und vergleichsweise dauerhafter kreativer Veränderungen: des Neuen. ${ }^{92}$ - Genau diesen Punkt, mitsamt der Interaktion von Pathologie und Produktivität, hat Bateson später mit Forschungen an Delphinen experimentell zu verifizieren gesucht, in einer Weise, die indirekt auch Rückschlüsse für die „Mechanik“ menschlicher Kreativität erlaubt. Der folgende Teil dieses Unterkapitels skizziert diese Forschungen im Hinblick auf Schlüsse für dasjenige, was an dem unkontrollierbaren und nicht voraussagbaren Phänomen der Kreativität verallgemeinerbar ist.

Zunächst: Wie kam es zu dem Übergang von Forschungen am Menschen hin zu solchen am Tier? Obwohl der theoretische Durchbruch seiner Kommunikationstheorie mit der „Entdeckung“ des Double-Bind einherging, als direkter Frucht der Typentheorie war, galt Batesons Hauptinteresse kommunikationstheoretischen Aspekten und dem Wunsch, die viel thematisierte digitale Kommunikation um Forschungsmaterial zur analogen Kommunikation zu ergänzen. Bereits vor seiner Zeit am Mental Research Institute in Palo Alto hatte er eine Zeitlang Unterschiede zwischen digitaler und analoger Kommunikation an Ottern studiert..$^{93}$

Überraschenderweise war es denn auch die anschließende, insgesamt acht Jahre währende Forschungsarbeit zur Intelligenz und Kommunikation bei Delphinen am Oceanic Institute in Hawaii bis 1971, der die ersten konkreten empirischen Beispiele für die These

92 Vgl. auch Watzlawick/Beavin/Jackson, Menschliche Kommunikation, S. 248 f.: „Es scheint bedeutsam, daß nur kurze Augenblicke der Erkenntnis auf der vierten Stufe möglich sind und diese nur sehr schwer, wenn überhaupt, in Worte gekleidet werden können. Der Leser dürfte sich erinnern, wie schwer es bereits war, den Sinn des Satzes ,Die Klassen aller Klassen, die sich nicht selbst als Element enthalten' zu erfassen, dessen Komplexität aber nur der einer Prämisse dritter Ordnung entspricht. In ähnlicher Weise ist es noch möglich, der Bedeutung von, So sehe ich, daß du dich von mir gesehen siehst' gedanklich zu folgen, während die nächste (vierte) Stufe (,So sehe ich, daß du siehst, daß ich mich von dir gesehen sehe') gedanklich bereits schwer faßbar ist - womit keineswegs gesagt sein soll, daß unsere Beziehungen nicht davon beeinflußt werden. Um diesen wichtigen Punkt noch mal zu wiederholen: Kommunikation oder sogar Denken über Prämissen dritter Ordnung sind nur von der vierten Stufe aus möglich, so wie in der Theorie der Sprachstufen Aussagen über eine Sprache nur von der nächsthöheren Stufe, also in der Metasprache, gemacht werden können. Die vierte Stufe aber liegt anscheinend bereits sehr nahe an den Grenzen menschlichen Erfassens, und Bewußtsein auf dieser Stufe besteht selten, wenn überhaupt. Dies scheint uns der Bereich der Intuition und der Empathie zu sein, des ,Aha'-Erlebnisses und vielleicht der unmittelbaren Wahrnehmungen, die gewisse Durchbruchserlebnisse vermitteln; und es ist sicherlich die Stufe, von der ... ein ... Wandel ausgeht, von dem man später nicht sagen kann, wie und warum er zustande kam und worin er eigentlich besteht." (Hvh. S. M.)

93 Vgl. Max Visser, „Gregory Bateson on Deutero-Learning and Double-Bind: A Brief Conceptual History“ sowie Bateson, Ökologie des Geistes, Vorwort. Batesons aus mangelnder institutioneller Unterstützung gescheiterte vorhergehende Arbeit mit Oktopussen sowie seine Motive dafür finden sich beschrieben in Lutterer, Spuren, S. 115 ff. 
des Entstehens kreativer Akte aus der Kollision logischer Ebenen entsprungen waren. ${ }^{94}$ Was diese Experimente jedoch zunächst erbrachten war der Hinweis auf das Vorkommen von „Deutero-“ bzw. Meta-Lernen bei Delphinen. Ein Delphin namens Malia war ausgewählt worden, in öffentlichen Shows die Prinzipien des „Delphin-Trainings“ vorzuführen. Gezeigt werden sollte einem Publikum, ,wie man einen Delphin dressiert“, und das Tier mußte dazu bei jeder Vorführung ein neues Kunststück, erlernen“. Das heißt, der Delphin schwamm ins Schaubecken, und sowie es irgend ein auffälliges Verhalten hinlegte, einen Schwanzschlag, eine besondere Drehung, einen Sprung, indizierte ein Pfiff des Dresseurs, daß eine Belohnung erfolgt, und er bekam einen Fisch. Nach dreimaliger Wiederholung eben dieser Folge - das Tier wurde ,konditioniert ${ }^{\text {- }}$ - wurde es zurückgeschickt, und nach zweistündiger Pause erfolgte eine neue Vorführung. Natürlich legte Malia dasselbe Verhalten an den Tag, für das sie in der Runde zuvor belohnt worden war und erwartete Pfiff und Futter - vergeblich. Erst als sie - wiederum zufällig - ein anderes auffälliges Verhalten an den Tag legte, wurde sie belohnt. Allerdings führte die vielfache vergebliche Vorführung zunächst belohnter Verhaltensweisen beim Delphin immer wieder zu Frustration.

Um die instruktive Geschichte abzukürzen: Was der Delphin in der Tat lernte, war naheliegenderweise eine Lektion ,zweiter Ordnung“, nicht, daß ein bestimmtes Verhalten zu bieten war, um die Belohnung zu erhalten, sondern daß bei jedem Auftritt eine andere Verhaltensweise zu bieten war (das Lernen einer Meta-Regel oder Lernen zweiter Ordnung). ${ }^{95}$ Der Delphin mußte eigenesVerhalten auf zwei Ebenen gleichzeitig klassifizieren: erstens als konkrete Einzelhandlung (das obige „Element“"), zweitens als „neu“ oder ,anders“ als die vorige: eine Meta-Klassifikation, ein Rahmen. Allerdings - und erst aus dem folgenden resultierte die eigentlich aufschlußreiche Erweiterung des theoretischen Rahmens, wie üblich aus einem Unfall - stieß das Experiment auf eine natürliche Grenze: dadurch, daß irgendwann das Repertoire neuer Verhaltensweisen, das der Trainer verstärken konnte, erschöpft war: ein Moment der Krise. Schließlich, in einer Phase hoher Erregung, legte das Tier plötzlich und unerwartet eine ganze Serie neuen Verhaltens an den Tag, einiges davon für Delphine vollständig ungewöhnlich: z. B. Auf- und Abspringen, mit-in-die-Höhe-gestreckem-Schwanz-Schwimmen etc.

Bateson war vom Ergebnis dieser Arbeit, an der er persönlich nicht beteiligt gewesen war, derart beeindruckt, daß er darauf drang, diese einmal beobachtete Entwicklung mit einem anderen Delphin zu wiederholen: in einem kontrollierten und streng protokollierten Experiment. Der zweite Delphin, wiederum ein weibliche Tier namens Hou, lernte

94 Zwischen 1964 und 71 war Bateson an einem Forschungsprojekt für das Oceanic Institute in Hawaii beteiligt. Die vergleichsweise ausführliche Zusammenfassung dieser Arbeit, auch auf der Basis der Publikationen von Karen Pryor, Leiterin des Forschungsprojekts, findet sich in Visser (2003), 273-275. - Konrad Lorenz äußerte nach einem Besuch in Hawaii, daß Bateson eines der ,größten biologischen Genies unserer Zeit" sei und noch nicht die ihm gebührende Aufmerksamkeit erfahren habe. Vgl. hierzu Lutterer, Spuren, S. 122. Zu den Gründen und Manifestationen von Batesons Interesse an Verhaltensforschung bei Tieren vgl. Lutterer, Spuren, S. 115-117, Max Visser, „Gregory Bateson on Deutero-Learning“, S. 273, Bateson, Ökologie des Geistes, S. 11-33.

95 Bateson stellt die Versuche und Ergebnisse sowohl in Ökologie des Geistes als auch in Geist und Natur dar; vgl. insbes. Bateson Geist und Natur, S. 153-156, ferner Ökologie des Geistes, S. 359 ff. Vgl. für ausführlichere Darstellungen und Hintergründe auch Visser, „Gregory Bateson on DeuteroLearning and Double-Bind“, S. 273-275. 
mit deutlich mehr Mühe und Frustration die Meta-Regel des „,neues-Verhalten-Zeigens“. Bei ihr verlief dieser Lernprozeß weniger sanft und vergleichweise schmerzfrei, sondern mit diversen Ausflügen in pathologisches, hochgradig verhaltensaufälliges Agieren. Die Erfahrung, ins Unrecht gesetzt zu werden, war für den Delphin so krisenhaft, daß der Dresseur viele Regel- bzw. Experiment-widrige Fische geben mußte, um den Kontakt zu dem Tier und die bisherigen Lernergebnisse nicht zu gefährden. Vor allem bot Hou erwartungsgemäß in jeder Vorführung zahlreiche vergebliche Wiederholungen eines Verhaltens, das in der Runde zuvor belohnt worden war - gleichsam, um den Dresseur doch noch des Unrechts zu bezichtigen. Neues Verhalten schien er zunächst nur zufällig an den Tag zu legen. Schließlich:

„In der Pause zwischen der vierzehnten und fünfzehnten Sektion schien der Delphin sehr erregt zu sein, und als er zum fünfzehnten Mal auftrat, legte er eine hochentwickelte Vorführung hin, in der acht auffällige Verhaltensweisen vorkamen, von denen vier völlig neu waren - etwas, das bei dieser Tierart noch nie beobachtet worden war. - Diese Geschichte veranschaulicht zwei Aspekte ... Erstens, daß starker Schmerz und Fehlanpassung induziert werden können, wenn man ein Säugetier bezüglich seiner Regeln ins Unrecht setzt, in einer wichtigen Beziehung zu einem anderen Säugetier Sinn zu stiften [regarding its rules for making sense of an important relationship with another mammal $\left.{ }^{96}\right]$. Und daß zweitens, wenn es gelingt, diese Pathologie abzuwehren oder zu überstehen, die Gesamterfahrung Kreativität fördern kann. ${ }^{\text {"997 }}$

Was hier geschah war die Erfahrung einer „logisch-unlogischen“ Situation, und das Tier fand schließlich die „Flucht“ aus diesem Double-Bind (von Verstärkung und Nicht-Verstärkung für Dasselbe) durch einen Sprung auf eine neue Kategorien-Stufe (,jedes Mal etwas neues Neues"). In anderen Worten: der Widerspruch, welchen das Lebewesen in der Interaktion mit seiner Bezugsperson erfährt, führte gerade bei Hou zunächst in pathologisches Verhalten und anschließend, mit der energetischen „Hilfe“ großer innerer Erregung, zu dem ,Spill-Over', als Sprung auf die höhere Kontextualisierungs-Ebene. Die Metapher des Sprungs indiziert das Überbrücken der Kluft zwischen den logischen Klassifikations-Ebenen. Generell provoziert der Umgang mit einem unlösbaren Widerspruch die Suche nach einem „Sprung“ hinaus: in den Bereich einer Regel-Dimension, auf welcher der Widerspruch keiner mehr ist. (Vielleicht sind gerade Delphine für eine solche Lektion ein Stück weit prädestiniert, insofern für ihre Physiologie ein kreativer Sprung hier mit einem buchstäblichen Sprung zusammenfällt und damit wiederum produktiv eine logische Diskontinuität erzeugt wie durchmessen wird.)

Interessanterweise wiesen beide Delphine, auch nachdem die Versuchsserie eingestellt worden war, anhaltende Charakter-Veränderungen auf, die nicht unproblematisch waren $^{98}$ - ein von Bateson nicht erwähnter Umstand, der gut in seine Theorie gepaßt

96 Bateson, Steps to an Ecology of Mind, S. 278

Bateson, Ökologie des Geistes, S. 360 f. Visser zitiert dazu den Bericht der Forschungsleiterin Karen Pryor: „After 32 sessions ... the behaviour of the porpoise became so complex that it could no longer be reliably discriminated and decribed by the observers, at which point the experiment was terminated.“ Visser, „Gregory Bateson on Deutero-Learning and Double-Bind“, S. 273.

„After the experiements, Hou and Malia remained highly creative in their behaviour, which for Hou in particular involved a definite change in ,character“. The dolphins became big nuisances, opening gates and even drawing the attention of trainers by leaving the water and sliding on the 
hätte: derzufolge dauerhafte Verhaltens- und Charakteränderungen möglich sind, wenngleich auf ggf. schwer erreichbaren und für das System durchaus risikoreichen indirekten Wegen des Agierens - die irreversibel sind.

Insgesamt läßt sich aus dieser Geschichte folgendes ableiten:

Erstens (Stochastik und Evolution): Entdeckungen kommen meist zufällig (,blind variation'), und es gilt, aus den unerwarteten Ergebnissen die richtigen Schlüsse zu ziehen (,selective retention'). Diese Schlüsse sind notwendig von einem höheren logischen Typ als die Beobachtungen: es sind Aussagen, Hypothesen über ganze Klassen von Phänomenen, weshalb - aus dem Schluß von Einzelfällen auf Allgemeines - Bateson auch zunehmend den Begriff der „Abduktion“ verwandte, um diese Hierarchie-Struktur zu beschreiben.

Offensichtlich hatte vor allem Hou, der zweite Delphin, in Sektion 1 bis 14 nur ,zufällig“" neues Verhalten an den Tag gelegt. Und der ,Durchbruch“ (in der Pause, in der er „sehr erregt“" war) wurde offensichtlich durch einen derartigen kognitiv-emotiven , Überdruck' (des fälschlich ins Unrecht gesetzt Werdens) möglich, daß der Delphin beim nächsten Mal zusätzlich zu den nicht gefragten vier alten nicht eine, sondern gleich vier neue Verhaltensweisen brachte: damit auch gleichsam seinen Dresseur ,ins Unrecht setzend“, indem er ihn überbot.

Zweitens (Pathogenese und Produktivität): Das starke Bild, daß aus einer intensiven kognitiven und begleitenden emotiven Dissonanz nach einer „Krise“ der „Durchbruch“ zum Neuen entsteht, aber eben vorbei an der riskanten (Übergangs-)Zone der ,Auflösung ' der alten Ratio des Indiviuums, zeigt gleichsam in nuce die Mechanik der Nähe von mentalen Höchstleistungen und Geisteskrankheit (pathologischer Dysfunktion): erstere werden buchstäblich ,,im Vorbeigehen“ den Abgründen letzterer abgerungen, und wenn der Sprung auf die höhere Ebene (einer Verallgemeinerung, die die Schmerz- oder Sinnlosigkeitserfahrungen im Nachhinein integriert) nicht gelingt, ist man nach einer solchen Erfahrung sicherlich schwerer beschädigt als vor ihr.

Generell lassen sich diese Lernprozesse, die von individuellen Leistungszuwachsen (Lernen 1) zu adaptiven Veränderungen des ganzen Charakters führen (Lernen 2 und höher), als ein rekursiver, also auf feedback-Mechanismen basierender Prozeß verstehen, der mit trial und error, Zufall und selektivem Vergleich arbeitet. Insofern verbindet diese Theorie des Lernens Elemente aus der Kybernetik mit solchen aus der Evolutionstheorie. Genauer: der evolutionstheoretische Mechanismus aus Zufall und positiver Verstärkung wird als feedback-Prozeß gedeutet, und dies auf mehreren, hierarchisch

pool pavement. In another experiment, a porpoise, after reliably showing correct responses, deliberately made a long series of $100 \%$ wrong choices to communicate the fact that the fish, used for reinforcement, was dried out and inedible. With the advent of fresh fish, the animal went back to a flawless performance." Visser, "Gregory Bateson on Deutero-Learning and Double-Bind", S. 274 (Quelle wiederum Pryor). Dies ist eine durchaus faszinierende Illustration einer Art von analoger Kommunikation (ich tue das Falsche) einer Negation (der Fisch ist nicht gut). Genaugenommen ist das Verhalten jedoch näher an der oben im Übergang vom bite zum nip beschriebenen Entwicklung hin zu einem Zeichen, das nicht das bedeutet, was es ist (Krieg, Biß) und damit hin zur digitalen Kommunikation. Insofern ist dieser Fall von größter und ungewöhnlicher Signifikanz. 
sortierten Ebenen. ${ }^{99}$ Es zeichnet sich hier ab, was im folgenden Kapitel deutlich wird: daß der geistige und der biologische Evolutionsprozeß nach denselben Prinzipien beschreibbar sind.

\subsection{Die Struktur der Evolution der Natur und des Geistes: Produktives Denken und Organisation als ,stochastisches ${ }^{6}$ Geschehen}

Es gibt Detaillücken zwischen Details. Wie feinmaschig unser Beschreibungsnetz auch sein mag, kleinere Details werden sich der Beschreibung immer entziehen. Dies nicht deswegen, weil wir etwa achtlos oder faul wären, sondern weil die Beschreibungsmaschinerie prinzipiell digital und diskontinuierlich ist, während die der zu beschreibenden Sache immanenten Variablen analog und kontinuierlich sind. Ist die Beschreibungsmethode jedoch analog, machen wir mit dem Umstand Bekanntschaft, daß keine Quantität irgendeine andere Quantität exakt wiedergeben kann-jede Messung ist immer und unvermeidlich eine Näherung.

Gregory Bateson

Batesons Äußerungen zur Kreativität in „Ökologie des Geistes“ lassen sich bislang im wesentlichen so zusammenfassen: Die Chance auf produktives oder schöpferisches Neues entsteht in einer , transkontexuellen ${ }^{\text {'Bewegung }}{ }^{100}$ zwischen zwei unterschiedlichen logischen Typen oder Ebenen: entsteht also, wenn die zwei divergierenden logischen Ebenen ,regelwidrig' zusammengebracht oder aufeinander bezogen werden, wenn die Grenze zwischen ihnen kollabiert. Zu den wesentlichen Weisen, in denen dies geschieht, zählen Phänomene wie Spiel, Humor, Ritus, Kunst, Religion, Metapher, Gleichnis und nicht zuletzt innovatives Wissenschaftshandeln. Wie am Beispiel von „bite“ und „nip“ schon angedeutet, hat vor allem das Phänomen des ,Spiels" in dieser Theorie einen zentralen Status: den eines hybriden (gemischten) Mittlers zwischen Stufen der Evolution des Denkens. Bateson bedient sich neben der analog-digital-Distinktion auch der Freud'schen Rede vom Primär- und Sekundärprozeß, um diese Ebenen zu beschreiben und gegeneinander abzugrenzen. Der Primärprozeß entspricht der ,analogen` Stufe mit ihrem Denken in Bildern, ihrer eingeschränkten Bewußtseinsfähigkeit, ihrem Kommunizieren über Beziehungen: alles Formen, die auch der tierischen Kommunikation eigen sind. Der Sekundärprozeß entspricht dem ,digitalen` Mitteilen mit seinen Formen der Sprache, Negation, Denotation, Wiederholung, Klassifizierung, formaler Logik etc. ${ }^{101}$ Die Mittler-Rolle des Spiels liegt darin, daß, wie dargestellt ${ }^{102}$, in ihm phänotypisch wie genotypisch erstmals in der Kommunikation „nein“ oder „nicht“ aktiv artikuliert sind:

99 Vgl. hierzu, sowie zur hierarchischen Komponente dessen Max Visser, „Gregory Bateson on Deutero-Learning and Double-Bind“, S. 275.

$100 \mathrm{Zu}$,transkontextuell“ vgl. Bateson, Ökologie des Geistes, S. 354 f.

101 Zur Relation von ,analog“ und „digital“ und der psychoanalytischen Terminologie von Primär- und Sekundärprozeß vgl. Mahrenholz, Musik und Erkenntnis, Kap. V., 2 sowie dies., „Logik, A-Logik, Analogik. Musik und die Verfahrensformen des Unbewußten“"

102 Vgl. oben Kap. 6.2. 
Die im Spiel gemachten Mitteilungen sind zugleich wahr und ,nicht wahr'; das mit ihnen Bezeichnete existiert in gewissem Sinne nicht. ,Ich beiße Dich' (nip) ist ein Zeichen für: ,Ich werde Dich nicht beißen“ (bite). Diese Möglichkeit, etwas Abwesendes mit etwas Anwesendem zu symbolisieren, diese Negation also ist es, die den entscheidenden Schritt nicht nur zur Sprache, sondern damit auch zu einer höheren Abstraktions-Ebene einleitet: vom „Territorium“ oder „Ding“ (etwa: Handlung) hin zur „Karte“ oder dem „Namen“ (etwa: Beziehungsstatus wie „Feind“ oder „Liebe“).

,Spiel' hat damit einen gleichsam doppelten Status, einen diachronen (die zeitliche Entwicklung betreffenden) und einen synchronen, simultanen. Einerseits ist es - diachron - in der Entwicklung der Kommunikation ein Schritt hin zu den arbiträren Zeichen der Sprache (und damit zum Denken als kontrafaktischem Probehandeln). Andererseits ist die ,Spiel'-Erklärung (wie auch komplementär die ,Kriegs'-Erklärung) synchron ein Shifter von Kontexten, der es ermöglicht, ein- und derselben Handlung ganz unterschiedliche Bedeutungen zuzumessen. ${ }^{103}$ Eben mit diesem Shift ,bricht“ Spiel die Diskontinuität zwischen beiden Ebenen (Aktion und ihrem Kontext) auf, oder, in anderen Worten: Spiel vermittelt zwischen den beiden ansonsten zueinander diskontinuierlich stehenden Seiten. Spiel ist ein Daimon. Wem dieser Gedanke willkürlich erscheint, der sei daran erinnert, daß bei Kant ebenfalls eine systematisch vermittelnde Rolle des ,Spiels ${ }^{6}$ zu finden ist. Hier sind es zwei gleichfalls diskontinuierliche, d. h. ansonsten unüberbrückbar voneinander geschiedene Fakultäten, „Einbildungskraft“ und „Verstand“, die über die Ausnahme-Situation des ästhetisch initiierten „,freien Spiels“ zueinander in „Harmonie“ treten. ${ }^{104}$ Wenn bei Bateson also Spiel diachron als Mittelglied zwischen Stufen der Evolution auftritt ${ }^{105}$ und synchron als Katapult hinaus in eine neue Ordnung, so fungiert es bei Kant ebenfalls synchron: als Mittler zwischen Einbildungskraft und Verstand. Auch hier führt Spiel hinaus und hinüber in eine andere Ordnung des Zusammenwirkens mentaler Fakultäten. ${ }^{106}$ Der späte Bateson wird schließlich, wie gleich markiert, „Ästhetik“ und „Epistemologie“" engstens miteinander verknüpfen. Auch hatte, wie wir uns erinnern, Platons Eros (,ein großer Zauberer“) die Rolle eines solchen Shifters zwischen ansonsten unüberbrückbaren Klüften von Ordnungen inne. ${ }^{107}$

103 In Michael Hanekes Film „Funny Games“ (1997/2008) bleibt die zuweilen fließende Grenze zwischen „Spiel“ und „Krieg“ lange auf grausam eindrückliche Weise im Unklaren. Manche Kämpfe, so Bateson, finden gerade statt, damit zwei Individuen/Parteien herausfinden, ob/daß sie Freunde (oder Feinde) sind, vgl. Ökologie des Geistes, S. 91 f. - Vgl. auch Donald W. Winnicott, Vom Spiel zur Kreativität: „Das Subjekt ... sagt zum Objekt: ,Ich habe dich zerstört,“ und das Objekt nimmt diese Aussage an. Von nun an sagt das Subjekt: ,Hallo, Objekt! Ich habe dich zerstört! Ich liebe dich! Du bist für mich wertvoll, weil du überlebt hast, obwohl ich dich zerstört habe. Obwohl ich dich liebe, zerstöre ich dich in meiner (unbewußten) Phantasie. “", ebd. S. 105.

104 Ausführlich dargestellt wurde dies oben, Kap. 4.3.3.

105 Vgl. Bateson, Ökologie des Geistes, S. 251

106 Vgl. Kant, Kritik der Urteilskraft, § 9 und $\S 21$. Zum Verhältnis dieser Konzeption zur Genietheorie vgl. oben 4.3.3. Kant betont ausdrücklich, daß es nicht-analysierbare Ausnahmebedingungen wie die Anwesenheit des Schönen oder die geniale Gestimmtheit des Subjekts sind, welche diese Harmonie bzw. wechselseitige Übersetzbarkeit stiften: das „Schöne“ "läßt sich mithin gerade auch bei Kant als ein solcher „Shifter“ zwischen mentalen Ebenen verstehen.

107 In seinem Fall waren es der göttliche und der menschliche Diskurs; vgl. oben Abschnitt 3.2.1. 
Die Eigendynamik dieser Verbindung zwischen Heterogenem wird von Bateson in den Jahrzehnten nach dem Erscheinen von Ökologie des Geistes 1972 immer wieder neu logisch und terminologisch umkreist. Das Thema wird in ähnlicher Weise Fokus eines Lebenswerks wie unter ganz anderen begrifflichen und systematischen Voraussetzungen die parallel plazierte Einbildungskraft bei Kant. Eine der charakteristischen Schwierigkeiten von Batesons Modell der Ergänzung der „,analog“-,,digital“-Unterscheidung durch die Figur der Meta-Ebenen liegt darin, daß die Frage, welche Seite von beiden „meta“ ist, über die andere, mehrdeutig bleibt. Das Verhältnis oszilliert, und dies nicht nur bei Bateson. ${ }^{108}$ Unvermindert und zu bis seinem Tod 1980 werden die Versuche fortgesetzt, ein gültiges Modell zu finden, das dieses Ebenenproblem löst, wobei der Allgemeinheitsgrad der hierzu verwendeten Begriffspaare stetig wächst. Zu ihnen gehören nun solche Abstrakta wie „Struktur und Prozeß“, „Ding und Relation“, „Epigenese und Evolution“. Vor allem aber auch „Zufall und Selektion“; was zusammen „Stochastik“ ergibt: eines der Grundprinzipien, dem Bateson alle geistigen und biologische Entwicklungen zuschreibt: die von Mind and Nature - wie seine einzige als Monographie verfaßte Publikation nicht ohne Grund heißt. ${ }^{109}$

Die folgenden Betrachtungen versuchen dasjenige, was Bateson Zeit seines Lebens intendierte: nämlich diese heterogenen Ansätze zusammenzufassen zu einer Art Modell. Denn mit der Frage, ob und wie Batesons Modell „hält“, ist zugleich die avancierteste (außerphilosophisch-)philosophische Kreativitätstheorie diskutiert, die mit einer Gedankenfigur arbeitet, die der hier verwendeten Grundidee verwandt ist und sie auf pan-disziplinäre Weise zu konkretisieren sucht.

Den Motor von Batesons Bemühungen bildet die Frage nach dem Zusammenhang von biologischer und geistiger Evolution. Dies ist eine Form der Frage nach Kreativität: verstanden hier vor allem als Weiterentwicklung auf immer komplexere und hochentwikkeltere Stufen biologischer und geistiger Organisation einerseits, als Frage nach „Lern“und Kognitionsformen andererseits.

Wie hängt beides zusammen, das Denken und das Sein? Inwiefern ist Epistemologie zugleich Ontologie? Aus diesen Fragen lassen sich alle weiteren Bateson'schen Motive ableiten: sie führen hin zur, Ästhetik' (im weiten Sinn als Organisation von Wahrnehmung ${ }^{110}$, im engeren Sinn als Bedeutung der Künste) sowie zu Fragen der Sinnhaftigkeit

108 Sehr deutlich findet sich diese Oszillation auch bei Anthony Wilden, System and Structure.

109 Diese auf den ersten Blick überraschende Parallelisierung von Geist und Natur, von Epistemologie und Biologie ist in der Philosophie nicht ohne Vorgänger: unter den neueren Autoren seien Friedrich Nietzsche, Henri Bergson, Alfred North Whitehead oder Susanne K. Langer genannt. Zu der Verbindung von Darwinismus bzw. Naturalismus und Philosophie vgl. Hans Lenk, Kreative Aufstiege, hier auch generell zur Verknüpfung von Naturalismus, Ontologie und Epistemologie.

110 Vgl. zu Batesons Konzept von „Ästhetik“ Bateson/Bateson, Wenn Engel zögern, ferner auch Bateson, Geist und Natur 16 f.: „Mit Ästhetik meine ich die Aufmerksamkeit für das Muster, das verbindet. ... Niemals Quantitäten, immer Gestalten, Formen und Relationen."Für eine solche, zugleich ästhetische und typentheoretische Betrachtung vgl. als Beispiel ebda $18 \mathrm{f}$.: „Die Anatomie des Krebses beruht auf Wiederholung und Rhythmus. Wie die Musik wiederholt sie mit Modulationen. In der Tat entspricht die Richtung vom Kopf zum Schwanz einer Zeitfolge: In der Embryologie ist der Kopf älter als der Schwanz. Ein Informationsfluß vom Vorder- zum Hinterteil ist möglich. ... 1. Die Teile jedes Mitglieds der creatura [Kreatur] müssen mit anderen Teilen desselben Indiviuums verglichen werden, um Verbindungen erster Ordnung zu ergeben. 2. Krebse müssen mit Hummern, Menschen mit Pferden 
des Ganzen (Holismus), in diesem Sinne der Religion. Der damit verbundene Grundgedanke ist der einer systemisch verfaßten ,ecology of mind“: eine Radikalisierung des Wissenschaftskonzepts der Kybernetik, an deren Entstehung Bateson wie erwäghnt als Gründungsmitglied der Macy-Konferenzen mit beteiligt war. ${ }^{111}$ Das kybernetische Vokabular implizierte ausdrücklich die Verbindung von Biologie, Technik und Sozialwissenschaften.

Nun sind die zwei eben genannten Fragen nach dem Denken und dem Sein, nach Epistemologie und Ontologie und nach geistiger und biologischer Entwicklung bekanntlich sehr unterschiedlich, und derlei zu vermischen (bzw. zu „,vermaschen“112) gilt philosophisch als typischer Kategorienfehler. Batesons vorsätzliches Verbinden dieser Fragen ist also ein selbstreferentielles Exempel jenes kalkulierten category mistake, den er beschreibt. Wenn er schöpferische Evolution und Lernen nicht nur als die epistemologische, sondern als ontologische Frage sieht, ist sein Verhältnis zur ,Realität' dabei jedoch nicht etwa von Hegel (Substanz-Subjekt-Identität), sondern eher von Kant geprägt: dessen Ansatz er wiederum eine besondere, ,relationale“ Pointe gibt. Sie lautet: das, was ,, ist “ (im metaphysischen, Beobachter-unabhängigen Sinne), ist zwar epistemisch nicht zugänglich (qua ,Ding an sich'), was jedoch zugänglich ist, sind Strukturen, Relationen zwischen dem, was ,ist". ${ }^{113}$ Bateson:

„Als Beobachter bin ich in einer Position, die der des Mathematikers ähnelt. Auch ich kann nichts über ein einzelnes Ding sagen, ich kann nicht einmal aus Erfahrung behaupten, daß ein solches existiert. Ich kann nur etwas über Relationen zwischen Dingen wissen. Wenn ich sage, der Tisch sei ,hart', gehe ich über das hinaus, was meine Erfahrung bezeugt. Was ich weiß, ist, daß die Interaktion oder Beziehung zwischen dem Tisch und einem Sinnesorgan oder Instrument einen besonderen Charakter differentieller Härte hat, für den ich kein angemessenes Vokabular habe und den ich verzerre, indem ich den besonderen Charakter der Beziehung völlig einer ihrer Komponenten zuschlage. Ich verzerre so das, was ich über die Beziehung wissen könnte, zu einer Aussage über ein ,Ding', das ich nicht wissen kann. Der Referent aller gültigen Aussagen ist immer eine Beziehung zwischen Dingen. “ 114

Das Ding „hinter“ der Relation wäre für uns ohnehin einigermaßen wertlos: es wäre, in Batesons Worten, „das Geräusch einer klatschenden Hand“"115. Damit ist das was ist,

verglichen werden, wenn man ähnliche Relationen zwischen den Teilen entdecken will (d. h. Verbindungen zweiter Ordnung). 3. Der Vergleich zwischen Krebsen und Hummern muß mit dem Vergleich zwischen Menschen und Pferden verglichen werden, um Verbindungen dritter Ordnung zu ergeben. Wir haben eine Stufenleiter des Denkens konstruiert ... Meine zentrale These läßt sich nun in Worten andeuten: Das Muster, das verbindet, ist ein Metamuster. Es ist ein Muster von Mustern.“

111 Zum Theorie-Einfluß der „Kybernetik“ auf Bateson vgl. auch unten 6.6 sowie Peter Harries-Jones, „Revisiting Angels Fear: Recursion, Ecology and Aesthetics“, insbes. 11-14.

112 Vgl. Bateson/Bateson, Wenn Engel zögern, S. 234.

113 Vgl. ebd. S. 222 ff., S. 66.

114 Ebd. S. 222 f., Hvh. S. M.

115 Bateson, Geist und Natur, S. 87 f. Dieser Gedanke im Gesamtkontext: „Es gibt eine tiefe und unbeantwortbare Frage hinsichtlich der Natur zumindest jener ,zumindest zwei` Dinge, die zusammen den Unterschied hervorbringen, der dadurch, daß er einen Unterschied macht, zur Information wird. Eindeutig ist jedes für sich - für den Geist und für die Wahrnehmung - eine Nicht-Entität, ein Nicht-Seiendes. Nicht unterschieden vom Seienden und nicht unterschieden vom Nicht-Seienden. Ein Unerkennbares, ein Ding an sich, das Geräusch einer klatschenden Hand.“ - Vgl. Bateson ebd., 
zugleich erkennbar und unerkennbar: auf gleichsam zwei verschiedenen logischen Ebenen:

„Es fällt ... schwer, die gewaltige geistige Organisation der Welt und ihrer Teile zu erörtern, aber mir scheint, wir können, wenn wir vorsichtig sind, darüber reden, wie diese gewaltige Organisation denkt. Wir können die Verknüpfungen erforschen, die sie zwischen ihren Aussagen benutzt, wohingegen wir niemals wissen können, was sie denkt." "116

(In gewisser Weise ist diese epistemisch-perspektivistische Doppelheit eine eigenständige Variante von Kants Doppel-Positioniertheit in der „Kritik der reinen Vernunft“: als zugleich transzendentaler Idealist und empirischer Realist.)

Bateson bemüht sich in „Geist und Natur" wie schon angekündigt um eine vereinigende Sicht auf die Evolutionsprozesse in beiden Phänomenen. Hierfür überträgt er zentrale evolutionstheoretische Grundmotive (Elemente von Darwin, Lamarck und Samuel Butler verbindend ${ }^{117}$ ) vom biologischen auf den geistigen Entwicklungsprozeß - dabei „geistig“, wie angedeutet, weitfassend. ${ }^{118}$ Jedes System oder Subsystem verbindet ihm zufolge eine Zufallskomponente und einen Selektionsprozeß, der auf die Produkte ersterer einwirkt. ${ }^{119}$ In dieser ,stochastischen“"120 Gleichzeitigkeit gegenstrebiger Prinzipien erkennen wir ohne Mühe das darwinistische Grundprinzip von „,blind variation“ und „selective retention“ wieder. ${ }^{121}$ Bateson begreift diese beiden gegenstrebigen Grundprinzipien auffallenderweise wiederum als eine Variante der Unterscheidung von ,,analog“ und ,digital“: nun aber typentheoretisch hierarchisiert. In der Tat ist die Selektion „über“ die Produkte des Zufalls oder der „,blinden Variation“. Sie greift bestimmte Komponenten heraus und ignoriert andere: in nichts anderem besteht Digitalisierung. Während auf der Ebene der Zufallsprozesse, der blinden Variation, eine Kontinuität besteht, im Sinne der Gleich-Gültigkeit beliebig feinkörnig gestreuter Varianten, „negiert“ der Selektions-Akt: validiert die einen um den Preis des Verlustes der anderen. In die Kontinuität des Vorhan-

S. 120: „Wir ziehen [draw] Unterscheidungen; das heißt, wir entnehmen sie. Die Unterscheidungen die nicht gezogen werden, existieren nicht. Sie sind für alle Zeiten verloren, wie der Klang des fallenden Baums, den Bischof Berkeley nicht hörte. Der Bischof meinte, daß nur das Wahrgenommene ,real' ist, und daß der Baum, der ungehört fällt, kein Geräusch macht. Meiner Ansicht nach können latente Unterschied, d. h. solche, die, aus welchem Grund auch immer, keinen Unterschied machen, nicht als Information gelten, sodaß ,Teile', ,Ganzheiten', ,Bäume ' und ,Geräusche' als solche nur in Anführungszeichen existieren. Wir sind es, die ,Baum`von ,Luft' und ,Erde‘ unterscheiden, ,Ganzes' von ,Teil' und so weiter."

116 Bateson/Bateson, Wo Engel zögern, S. 222 f.

117 Vgl. etwa Geist und Natur S. 30; zu Batesons Darwin-Kritik vgl. Harries-Jones, A Recursive Vision: Ecological Understanding and Gregory Bateson, insbes. S. 160-164.

118 Was für einen „Geist“-Begriff legt Bateson zugrunde? Evidenterweise einen sehr weiten. Vgl. hierzu vor allem Geist und Natur Kap. I. und insbes. Kap. IV. „Definition“, hier insbes. S. $113 \mathrm{ff}$.

119 Vgl. Bateson, Ökologie des Geistes, S. 220.

120 Bateson verwendet den Begriff „stochastisch“ als Oberbegriff, von dem „Selektion“ ein Unterbegriff ist. („Wenn eine Abfolge von Ereignissen eine Zufallskomponente derart mit einem selektiven Prozeß kombiniert, daß nur bestimmte Ergebnisse des Zufallsfaktors Bestand haben dürfen, heißt diese Abfolge stochastisch.“ Bateson/Bateson, Wo Engel zögern, S. 297 u. ö. Gewöhnlich steht „Selektion" für das Ergebnis dieses kombinierten Prozesses.)

121 Vgl. zu dieser evolutionären Kreativitätstheorie den klassischen Text von Donald T. Campbell (1960), „Blind Variation and Selective Retention in Creative Thought as in Other Knowledge Processes“. 
denen werden bewertende Schneisen geschlagen (ja/nein; 1/0). Die Selektionsprozesse bewirken indirekt Negation durch Nicht-Verstärkung. Damit ist das klassifizierende Selektionsprinzip ein Prinzip , endlicher Differenzierung“.

Charakteristischerweise sind beide Prinzipien, Variation und Selektion, vom Zufall mitgestaltet: nichts in ihnen determiniert, wie sie stattzufinden haben. Vielmehr sind sie von den externen Faktoren der Umwelt (auf biologischer Ebene) und des Kontexts, Interesses oder Problems (auf geistiger Ebene) geprägt. Innerhalb dieses stochastischen Gesamtsystems der Weiterentwicklung läßt sich besagte Relation auch mit einem anderen, bekannten Begriffspaar beschreiben: „Epigenese“ und „Evolution“ (bzw. „kreative Weiterentwicklung“"). ${ }^{122}$ Auf biologischer Ebene ist „Epigenese“ die Ausfaltung jener „Tautologie“"123, welche die genetische Information beinhaltet und sichert, daß es nicht zu zu starken Abweichungen kommt. Epigenese betrifft also den Genotypus, das innere System und hat eine ,konservative' Ausrichtung. Evolution hingegen (im kreativen Sinn der Entstehung neuer Arten) betrifft das Umwelt-Moment bzw. vollzieht sich in beweglicher Interaktion mit kontingenten Umweltfaktoren, welche aus der zufälligen Streuung von Varianten bestimmte herausselektieren.

„Die Evolution muß immer janusköpfig in zwei Richtungen weisen: nach innen, auf die Entwicklungsgesetze und die Physiologie des lebendigen Geschöpfs, und nach außen, auf die Launen und Anforderungen der Umgebung. ... Die innere Entwicklung - die Embryologie oder Epigenese - ist konservativ und verlangt, daß alles Neue mit den Regelmäßigkeiten des status quo ante übereinstimmt." 124

Eben diese Paarung aus interner Konservativität und externer Variabilität - das Merkmal der ,kreativen“ Ausgangssituation - ist nach Bateson wiederum auch im Geistigen aufweisbar: Auf der Ebene des Lernens und der geistig-kulturellen Weiterentwicklung beinhaltet „Epigenese“ damit die Gebote der Kohärenz und der Logik, „Evolution“ hingegen die ,spontane " Streuung, Neuverteilung und Neukombination von Ideen. ${ }^{125}$ Dies entspricht der Gleichzeitigkeit von Strenge und Phantasie, Strenge als „Analogon der inneren Kohärenz in der Evolution, ${ }^{126}$ Phantasie hingegen als Analogon der Streuung und entsprechend der in Teilen, blinden' Schöpfung neuer und abweichender Ideen, und beide zusammen als jene ,,großen Gegensätze des geistigen Prozesses, von denen sich jeder für sich genommen tödlich auswirkt. Strenge allein ist lähmender Tod, aber Phantasie allein ist Geisteskrankheit"“. ${ }^{127}$

Wie sich oben bereits zeigte, faßt Bateson mit der Differenz von Zufall und Selektion auch jene der unterschiedlichen logischen Ebenen oder Typen als eine Form der ana-

122 Vgl. zu dieser Unterscheidung Bateson, Geist und Natur, Kap. VI, insbes. S. 202-206, 219-231, ferner S. $63 \mathrm{f}$.

123 Zum Verhältnis von „Beschreibung“, „Erklärung“ und „Tautologie“"vgl. Bateson, Geist und Natur, S. 103-112.

124 Bateson/Bateson, Geist und Natur, S. 267.

125 Bateson, Ökologie des Geistes, S. 230.

126 Ebd. S. 231. Deutlich dürfte sein, inwiefern in dieser Paarung sowohl die Ausgangsidee von endlichem und unendlichem Differenzieren widerhallt als auch Kants oben wiedergefundenes „Spiel“ der Erkenntniskräfte Verstand und Einbildungskraft in der Kritik der Urteilskraft.

127

Bateson/Bateson, Geist und Natur, S. 265. 
log-digital-Unterscheidung. Sie betrifft in anderen Worten das Verhältnis von Ding bzw. Geschehnis einerseits, deren Variablen immer analog und kontinuierlich verfaßt sind, und dazugehörigen Bezeichnungen (Klassifizierungen) andererseits, welche prinzipiell digital und diskontinuierlich sind. ${ }^{128}$ Die zentrale Frage richtet sich auf die Möglichkeiten, ihrer Interaktion:

„Schließlich ist es notwendig, die beiden stochastischen ...[Seiten] ${ }^{129}$ zusammenzufügen, die ich zum Zwecke der Analyse getrennt habe. Welche formale Relation besteht zwischen ihnen? Wie ich es sehe, liegt die Wurzel des Problems im Kontrast zwischen dem Digitalen und dem Analogen, oder, in anderer Terminologie, zwischen dem Namen und dem benannten Prozeß. “130

Zumindest für den späten Bateson ist die mit der analog-digital-Differenz verknüpfte Frage nach dem Verhältnis von Prozeß und Struktur (bzw. hier: Name) die Frage schlechthin: Prozeß einerseits als der erwähnte singuläre, analoge und nie in seiner singulären und analogen Fülle und Multiperspektivität wahrnehmbare Fluß der Dinge - Struktur andererseits als Umstand, daß alles Organische (das bei ihm, da genetisch bestimmt, ebenfalls als „Geistiges“ firmiert) nach klar erkennbaren, wiederholbaren (und darin digitalen) Mustern, Relationen organisiert ist. Letztere finden sich einerseits in genetischen ,Bauplänen', andererseits beobachtet das Forscherauge ununterbrochen Strukturen: qua Ähnlichkeiten und Verwandtschaften. Wir finden in der Natur wieder und wieder dieselben Formen; Bateson akzentuiert hier den auf biologischer Ebene überall zu findenden ,kybernetischen' Aspekt der Selbst-Ähnlichkeit oder Rekursivität (,feedback-loops"). In dem letzten großen Kapitel aus „Geist und Natur" entwickelt er ein Schema, das versucht, diese beiden Prinzipien in einen engen systematischen $\mathrm{Zu}$ sammenhang zu stellen und damit ein übergreifendes Modell von geistiger Kreativität und biologischer Evolution anzubieten.

\subsection{Die Denk-Spirale}

Alle Teile des Organismus bilden einen Kreis. Daher ist jeder Teil sowohl Anfang als auch Ende.

Hippokrates

Dieses finale Zusammendenken aller beteiligter Komponenten initiiert eine neue Phase in Batesons biologisch-epistemologischer Rekonstruktion der Russell'schen Typen-Hierarchie. ${ }^{131}$ Während er zunächst feststellte, daß der Proze $\beta$, qua analoger Fluß, kontinuierlich verfaßt ist, und daß die - u. a. begriffliche, aber z. B. auch DNA-förmige - Struktur, als digitale, auf einer höheren logischen Ebene und „über“ den analogen Prozeß ist, konsta-

128 Und zwar syntaktisch digital und diskontiniuerlich. Zur syntaktischen Digitalität von Sprache vgl. oben Kap. 5.3. sowie Goodman, Languages of Art, Kap. IV, 2.

129 Bateson spricht hier von „Prozessen“.

130 Bateson, Geist und Natur, S. 232.

131 Vgl. auch Bateson, Geist und Natur, S. 240, 244, ferner Bateson/Bateson, Wo Engel zögern, S. 64 68. 
tiert er in einem weiteren Schritt wie angedeutet, daß auch die Struktur-schaffende Namens- oder Klassenbildung selbst einem Proze $\beta$ unterliegt ${ }^{132}$, der Prozeß also auch ,über“ die Begriffsstruktur oder Klassen-Ebene ist. So ist es wiederum diese Paarung von Prozeß und Struktur/Klasse, welche in einer hierarchischen Form der Abstraktion auftritt.

\begin{abstract}
„Was in den Principia ${ }^{133}$ als eine gleichartige Stufenleiter erscheint (Namen und Namen von Namen und so weiter), wird zu einer alternierenden Anordnung von zwei Arten von Stufen. Will man vom Namen zum Namen des Namens gelangen, so muß man den Prozeß der Benennung des Namens durchlaufen. Es gibt immer einen Entstehungsprozeß, durch welchen die Klassen hervorgebracht werden, bevor man sie benennen kann." ${ }^{\text {"134 }}$
\end{abstract}

Dieser Gedanke erweitert das typentheoretische Modell, indem er die Hierarchie zwischen höherem und niedrigerem logischen Typ und zwischen „Analogem“/Prozessualem und „Digitalem“/Strukturellem komplexer und quasi oszillierend faßt. Bateson konstatiert selber die Grenzen der Artikulation und Faßbarkeit der hier zu beschreibenden Verhältnisse: statt die Beschreibung dieses Verhältnisses als den ,schwierigsten und vielleicht wichtigsten Teil des Buchs“" bezeichnend. ${ }^{135}$
„Aus dem bereits Gesagten ist klar, daß die Struktur sowohl den Prozeß determinieren kann als auch umgekehrt. Daraus folgt, daß eine Relation zwischen zwei Ebenen von Strukturen bestehen muß, wobei die Vermittlung durch eine dazwischentretende Beschreibung des Prozesses hergestellt wird. Ich glaube, das ist die in der realen Welt gegebene Analogie zu Russells abstraktem Schritt von der Klasse zur Klasse der Klassen."136

Was ist hier die Pointe? Es werden (nun) nicht mehr nur unterschiedliche logische Ebenen von Klassen unterschieden, sondern auch unterschiedliche logische Ebenen von Prozessen: Da ist einerseits der Prozeß der Klassen-Bildung (Kategorie-Bildung), also der Herausbildung des ,Namens', unter dem klassifiziert wird, andererseits der Akt der Benennung/Klassifizierung selber. Diese beiden Seiten werden von Bateson dann als „Prozeß“ und „Form“ auseinandergenommen. Der „Prozeß“ besteht darin, zu einer individuellen Sache, Handlung, Sachverhalt den Begriff zu finden (aus einer Reihe von Alternativen) oder neu zu bilden - je nachdem wie kreativ oder alltäglich die Aufgabe ist. Diesen Begriff dann applizieren heißt, von einer bereits feststehenden Form oder Kategorie Gebrauch zu machen. (Kant unterscheidet eben diese Aufgaben als ,reflektierende“ und „,subsumierende“ Urteilskraft.) Ersteres, das Erstellen des Allgemeinbegriffs, des „,sets“, ist die anspruchsvollere Tätigkeit - die Typisierung oder Klassifizierung (,Struktur") ist dagegen routinemäßig erlernbar. Der kognitiv fordernde ,reflektierende“ Akt ist jener ,von unten nach oben' aufsteigende und dabei abstrahierende: jener der Kategorie-Bildung. Der umgekehrte, subsumierende, ,von oben nach unten' verlaufende Akt ist von

\footnotetext{
132 Vgl. v. a. Kap. VII von Bateson, Geist und Natur sowie Bateson/Bateson, Wo Engel zögern.

133 Gemeint sind die Principia Mathematica (1910-1913) von Russell und Whitehead.

134 Bateson, Geist und Natur, S. 233, Hvh. S. M.

135 Bateson, Geist und Natur, S. 220, Fußnote. Dabei handelt es sich insbesondere um den Schlußabschnitt „Vergleich und Kombination der beiden stochastischen Systeme“ des Kapitels VI, das den „großen stochastischen Prozessen“ gewidmet ist.

136 Bateson, Geist und Natur, S. 243.
} 
ersterem determiniert. ${ }^{137}$,Proze $\aleph^{\text {‘ }}$ produziert erst ,Form', könnte man sagen. ${ }^{138}$ Klar ist in typentheoretischer Perspektive, daß sich das auf mehreren Ebenen wiederholt.

Zur Darstellung dieses Umspringens unter den Ebenen, dieser hierarchischen Alteration von „Prozeß“ und „Form“, schlägt Bateson in seinem Spätwerk das Modell einer aufsteigenden Zickzacklinie vor. Er präsentiert diese im wesentlichen anhand dreier Beispiele: seiner Analyse der neuguinesischen Kultur der Iatmul, wie er sie in dem frühen ethnologischen Buch „Naven“ beschrieben hat, ${ }^{139}$ ferner der Funktionsweise eines Heizthermostats sowie des Schießens mit einem Gewehr im Unterschied zum Schießen mit einer Schrotflinte. ${ }^{140}$ Wir werden nur das erste Beispiel etwas näher vorstellen. ${ }^{141}$ Vor allem aber verdeutlicht jenes erste Beispiel die Genealogie der Russell überbietenden Idee der Herausbildung der Kategorie.

Bei der Untersuchung der Iatmul auf seiner zweiten Reise nach Neuguinea 1936 (in deren Verlauf er auch sein Konzept der „Schismogenese“ konturierte) begegnete Bateson einer Fülle von Kategorien, die er von erfahrenen Ethnologen vorgegeben bekam: darunter von Margaret Meads Sex and Temperament ${ }^{142}$ (1935), Ruth Benedicts Patterns of Culture (1934) sowie Ernst Kretschmers Körperbau und Charakter (1921). Konfrontiert dabei mit einer Fülle ererbter und sich gegenseitig durchdringender Begriffspaare (wie Benedict/Nietzsches „,apollinisch“ und „dionysisch“ oder Kretschmers ,zyklothom“ und „schizothom") realisierte er schnell die produzierende Kraft - und damit auch die Relativität - begrifflicher Typologien. Er behandelte diese Typologien ,als eine abstrakte Karte, deren Raster ich über meine Beschreibung von Iatmul-Männern und -Frauen warf", ${ }^{143}$ und das Studium des Effekts der Abgrenzungen führte seine eigene Forschung schnell auf Fragen der Entstehung von Typologien - von ihm beschrieben im Zusammenhang mit seiner Herausbildung des „Schismogenese“-Konzepts.

„Mit anderen Worten, ich ging von einer Klassifizierung oder Typologie zu einer Untersuchung der Prozesse über, die die in der Typologie zusammengefaßten Unterschiede hervorbrachten. Aber der nächste Schritt führte vom Prozeß zu einer Typologie des Prozesses. Ich etikettierte die Prozesse mit dem allgemeinen Terminus Schismogenese, und nachdem ich die Prozesse mit einem Etikett versehen hatte, ging ich dazu über, sie zu klassifizieren. Mir wurde klar, daß eine grundlegende Dichotomie möglich war. Die Interaktionsprozesse, die an der allgemeinen Potentialität teilhatten, die Schismogenese zu fördern ... ließen sich

137 Hier lassen sich natürlich ,Deduktion“ und ,Induktion ‘ assoziieren - Bateson selber bevorzugte den Peirce'schen Begriff der ,Abduktion‘. Vgl. etwa Geist und Natur, S. 108-110, u. ö.

138 Kant hat genau jenes Problem, das der Erstellung von Kategorien, Klassen, Begriffen, als jene rätselhafte Tätigkeit identifiziert, welche in den „dunklen“ Bereich der Einbildungskraft, Urteilskraft und des Schematismus gehört. Er artikulierte in diesen Konzepten, daß das epistemologisch Interessanteste vor der Herausbildung der Begriffe liegt. Vgl. oben Kapitel 4.4.

139 Gregory Bateson (1936), Naven. A Survey of the Problems suggested by a Composite Picture of the Culture of a New Guinea Tribe drawn from Three Points of View.

140 Sämtliche Beispiele samt der Darstellung der gesamten Idee finden sich in Bateson, Geist und Natur, Kap. VII: „Von der Klassifizierung zum Prozeß“, vgl. insbes S. 240, 244.

141 Dies auch deswegen, weil die beiden anderen in Batesons Schriften vergleichsweise ausführlich diskutiert sind; vgl. vorige Fußnote. Eine teilweise veränderte Wiederaufnahme dieser Motive findet sich in Bateson/Bateson, Wo Engel zögern, Kap. IV, inbes. S. 64-68 sowie ebd. S. 235, inbes. Fußnote.

142 Vgl. Margaret Mead, Sex and Temperament in Three Primitive Societies (1935)

143 Geist und Natur, S. 237, engl. 212, leicht abgewandelte Übersetzung, Hvh. S. M. 
in zwei große Gattungen klassifizieren: die symmetrischen und die komplementären. Ich wandte den Terminus symmetrisch auf all jene Interaktionsformen an, die sich mit Hilfe von Konkurrenz, Rivalität, wechselseitiger Überbietung und so weiter beschreiben ließen ... Im Kontrast hierzu wandte ich den Terminus komplementär auf Interaktionssequenzen an, in denen die Handlungen von A und B verschieden, aber wechselseitig zueinander passend waren (z. B. Herrschaft - Unterwerfung, Exhibitionismus - Voyeurismus, Abhängigkeit - Versorgung). ... An diesem Punkt verfügte ich über eine Klassifizierung oder Typologie nicht von Personen, sondern von Prozessen. ... Ich war ohne, dies bewußt geplant zu haben, auf einer alternierenden Stufenleiter von der Beschreibung zum Vokabular der Typologie vorangeschritten. " 144

Die Russell'sche Idee, Namen oder Kategorien nach aufsteigenden Hierarchien von Abstraktionsebenen zu ordnen, überträgt Bateson - zumindest in seiner rückblickenden Analyse - auch auf die Prozesse, aus welchen jene Kategorien hervortreten, und ordnet sie ebenfalls hierarchisch. Hieraus resultiert eine Zickzacklinie, welche die Abstraktionsebenen wie Produktions- und Abhängigkeitsrelationen beider Seiten symbolisiert. Bateson liefert hierfür eine Fülle unterschiedlicher und im Detail konfligierender Beschreibungen. Aus ihnen konstruieren wir folgendes Schema - wiederum von unten nach oben zu lesen. ${ }^{145}$

\section{Form/Struktur, Klassifizierung (digital)}

(S3) ...

(S2) Typen von InteraktionsThemen (Regeln, Gesetze), (Vergegenständlichung/ Abstraktion, Klasse der Klassen)

(S1) Typologie der Handelnden/ der Gegenstände, (Vergegenständlichung/ Abstraktion, Klasse)

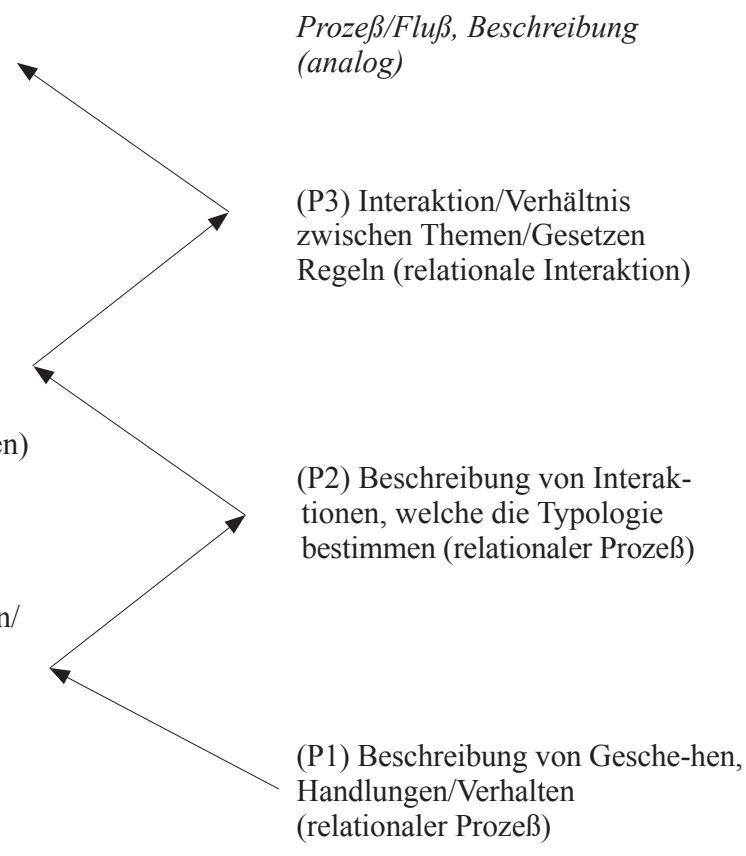

Illustration 2

\footnotetext{
144 Geist und Natur, S. 238 f.

145 Vgl. insbes. Bateson, Geist und Natur, Kap. VII; entsprechendes auch in Bateson/Bateson, Wo Engel zögern. Seine Darstellungen wurden unsererseits ergänzt um die Klassifizierungen zum Prozeß P1-3, S1-3.
} 
Auf der untersten Ebene (P1) haben wir die Beschreibung individueller Geschehnisse oder Handlungen, die uns als kontinuierlich sowie als Individuelles (als Analoges) begegnen. Im kognitiven oder auch nur wahrnehmenden Umgang mit dieser basalen Prozeß-Ebene geschieht, oft unwillkürlich, der Prozeß der Klassen- oder Namen-Bildung, mit dem die Typisierung vorgenommen wird. Für Bateson ist daher auch bereits der Wahrnehmungsprozeß ein „Akt der logischen Typisierung“!146 Im genannten Iatumul-Beispiel ist dieser Prozeß der Gewinnung von Klassifizierungen die Beschreibung konkreter Verhaltensweisen. Dieser Prozeß P1 der Klassenbildung (ausgehend von dem ,Material', das oben als „erster logische Typ“ oder „Aussage nullter Ordnung“ beschrieben wurde ${ }^{147}$ ) führt auf eine nächste Ebene („Form“ oder „Struktur“: S1), auf welcher wir etwas - ein Geschehen, einen Prozeß - klassifiziert vorfinden: als Sturm, Nebel, Iatmul-Frau, den Vermieter oder die Handlung des Segnens. (In Batesons Beispiel wird vom Handlungsgeschehen auf Personen und dann auf deren Charaktere abstrahiert.) Der nächste Schritt, auf ,höherer' Ebene ,zurück' von S1 zu P2 ist jener von typisierten Personen zu typisierten Beziehungen, Interaktionen: Prozeß- bzw. Interaktionsklassen. In seinem Beispiel sind dies: komplementäre und symmetrische „Schismogenese“. Diese Begriffsbildungsprozesse (P2) wiederum dienen dazu, die Typologie auf der Ebene S2 hervorzubringen: von ihm als „Regeln“, „Gesetze“ beschrieben: Regeln etwa, nach denen sich komplementäres oder symmetrisches Verhalten klassifizieren lassen, die also potentiell in psychologische Lehrbücher eingehen können, als Definitionen bzw. Typologien von Symptomatiken. Von hier an aufwärts wird es schwieriger, Beispiele anzugeben, weil die Abstraktionsebenen immer umfassender und damit unschärfer werden. ${ }^{148}$

Damit findet sich wiederum die oben in Abschnitt 6.1 beschriebene grundsätzliche Ebenen-Paarung. Allerdings herrscht nun die beschriebene Oszillation bezüglich der Frage, ob der Prozeß „über“ die Struktur oder die Struktur „über“ den Prozeß ist (bzw. ihm vorausgeht): wie wir sehen, ist beides der Fall. Die Klassifizierung geschieht immer von oben, aber die Bildung von Klassen ,über“ den Prozeß geschieht von unten.

Folgende Beispiele aus gänzlich unterschiedlichen Lebensbereichen lassen sich für die beiden Seiten von Prozeß/Fluß/Individuellem einerseits, Struktur/Form/Kategorie/ Typ andererseits nennen.

146 Geist und Natur, S. 235 - entsprechend Goodmans sehen-als; vgl. Nelson Goodman, Languages of Art, Kap. I. Oft bilden wir Kategorien, ohne es zu merken - diese sind vermutlich mindestens so häufig nonverbaler (sinnlicher oder gestalthafter oder gemischter) wie verbaler Art.

147 Vgl. oben Kap. 6.1.

148 Allgemeinere Beispiele für den Übergang von S1 zu P2 und höher zu S2 bestünden etwa darin, aus bestimmten Interaktionen eines Individuums mit seiner Umwelt (= Produkt der Transformation von P1 zu S1) auf eine individuelle Handlungsdisposition zu schließen (Produkt des Transfers von S1 - P2) und von dort eine solche verallgemeinerbare (,klinische“) Charakterdisposition, sprich, Metaklassifizierung zu bilden (hysterisch, Paranoia etc.). 


$\begin{array}{ll}\text { Prozeß/Fluß } & \text { Struktur/Form }{ }^{149} \\ \text { konkrete Temperatur } & \text { Thermostat }{ }^{150} \\ \text { Ding, Akt } & \text { Kategorie } \\ \text { Quantität } & \text { Qualität, Zahl, Muster } \\ \text { Kontinuität } & \text { Diskontinuität } \\ \text { Variationsprozeß } & \text { Artenbildung } \\ \text { Ausbildung } & \text { Beruf/Status } \\ \text { Liebe } & \text { Heirat } \\ \text { Rückkopplung } & \text { Kalibirierung } \\ \text { „Geist“ } & \text { "Buchstabe“ } \\ \text { Phantasie } & \text { Strenge } \\ \text { „Handeln“ } & \text { „Denken“ } \\ \text { "Zufälliges Auftretendes“/Kontingentes } & \text { „Selektiertes“ } \\ \text { somatische/ontogenetische Veränderung } & \text { phylogenetische Veränderung } \\ \text { Musik } & \text { Notation }{ }^{151}\end{array}$

Deutlich wird, daß beide Seiten für sich, isoliert, als Einzelebene nicht existieren, vielmehr , dialektisch" und komplementär aufeinander bezogen sind. Dies gilt, obwohl viele der Paare einander diametral entgegengesetzt sind, bis hin zu in einigen Fällen einander inkommensurabel gegenüberstehen. Die rechte Seite (Struktur, Klasse) geht immer aus der linken hervor (per Abstraktion, Erfahrung, Abduktion), ist aber immer über die linke; sie klassifiziert sie. Klassifizierung ist temporal später und logisch früher als das Phänomen.

Unser Modell in Illustration 2, die alternierende Schichtung, hat damit einen gegenüber Russells Ausgangsmodell erheblich erweiterten Anwendungsradius. Doch war Batesons genannte Kautele, es handele sich hier um den schwierigsten Teil seiner Darstellungen, Symptom eines Problems, das sich schon beim reinen Beschreiben immer wieder einstellt: daß die Beispiele für die Prozeßseite letztlich immer schon auf die Struktur-Seite tendieren, man kann auch sagen: daß Abstrakta wie die reine Wahrnehmung, das reine

$149 \mathrm{Zu}$ diesen Beispielen vgl. Bateson, Geist und Natur, S. 241, ferner ebda S. 270.

150 Der Heizthermostat ist Batesons favorisiertes Beispiel für ein Ineinander analoger und digitaler Strukturen, u. a. weil es den kybernetischen (,feedback“") Aspekt seines Modells veranschaulicht. Die kontinuierlich (,analog $\left.{ }^{6}\right)$ schwankende Temperatur auf der Prozeßseite bewegt sich zwischen zwei Polen, die ein auf Schwellenwerte eingestellter Thermostat regelt, der sich dadurch „digital“ an- oder ausstellt - die Strukturseite. Das ganze System ist kreisförmig-rekursiver oder auch autopoietischer Natur (vgl. Bateson/Batson, Wo Engel zögern, S. 60-66). Humberto Maturana hat im Anschluß an Bateson eine solche Analyse auf lebende Systeme als ganze angewendet, ja, Leben als autopoietisches System definiert. (Niklas Luhmann hat dies wiederum auf soziale Systeme übertragen, und der ungarische Biologe Tibor Ganti hat etwa zeitgleich mit Maturana/Varela ein ebenfalls rekursives (,autokatalytisches“) System als Definition der Struktur des „Lebens“ entwickelt. Zum Verhältnis von Bateson und Maturana/Varela vgl. Harries-Jones, „A Recursive Vision: Ecological Understanding and Gregory Bateson".

151 Zur logischen Stellung der Notation innerhalb des Musik-Partitur-Verhältnisses vgl. Verf., „,Der notationale Fehlschluß" sowie dies., Musik und Erkenntnis, Kap. III. 
Phänomen, der Fluß, das Ding-ohne-Struktur im Moment ihres Gedacht-Werdens schon zerfallen. Es heißt in anderen Worten, daß die Idee einer Meta-Ebene des Analogen, des Prozessualen (welches ja zugleich das Konkrete, Individuelle, Einzigartige, nicht-Kopierbare beinhaltet) sinnwidrig ist: das Meta-Individuelle ist nicht selbst individuell. Ein "Meta“ des Analogen, das wiederum selbst analog und prozessual wäre, sich aber diskontinuierlich zu einem Teil seiner selbst verhielte, ist selbstwidersprüchlich, und dies hat Bateson Jahre nach Geist und Natur zu einer Korrektur veranlaßt. Er betrachtet es nun als Irrtum, die „Prozeßseite“ als aus diskontinuierlichen Schritten, Stufen bestehend aufzufassen. Das heißt in unserer Terminologie: P1, P2, P3 sind untereinander als ein kontinuierlicher Proze $\beta$ zu verstehen, und dies horizontal wie vertikal: in ihrer internen Struktur wie in ihren Verbindungen untereinander. ${ }^{152}$

Wie läßt sich dies nun konzipieren? Es legt einen neuen, Bateson korrigierenden Theorie-Vorschlag nahe. Betrachten wir noch einmal das von ihm mehrfach exponierte Zickzack-Paradigma: nun in abstrahierter Form, wobei die linke Seite die Struktur, die rechte Seite den Prozeß darstellen.

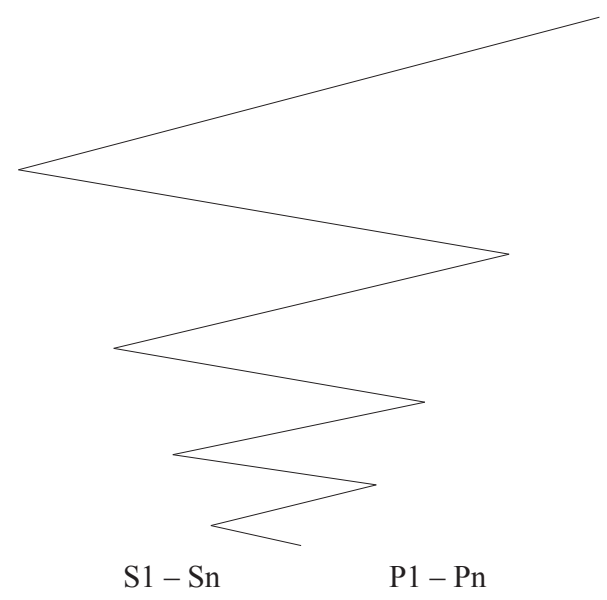

Illustration 3

Wiederum lösen sich Probleme, indem man eine weitere Dimension hinzufügt. In diesem Fall, so der hier unterbreitete Vorschlag, gilt es, das zweidimensionale Zickzack-Paradigma durch das Bild einer sich weitenden Spirale (Helix, Schraube) zu ersetzen. Das bedeutet nichts anderes, als sie um eine weitere Raum-Dimension zu erweitern: Eine Spirale von der Seite gesehen ist eine Zickzacklinie..$^{153}$

152 Vgl. Bateson/Bateson, Wo Engel zögern, S. 235, Fußnote.

153 Der Weg eines Besuchers in der gläsernen, spiralförmigen Berliner Reichstagskuppel bei Nacht, dessen Kleidung leuchtete, würde aus größerer Distanz als Zickzackbewegung gesehen - hier sich nach oben verjüngend. 


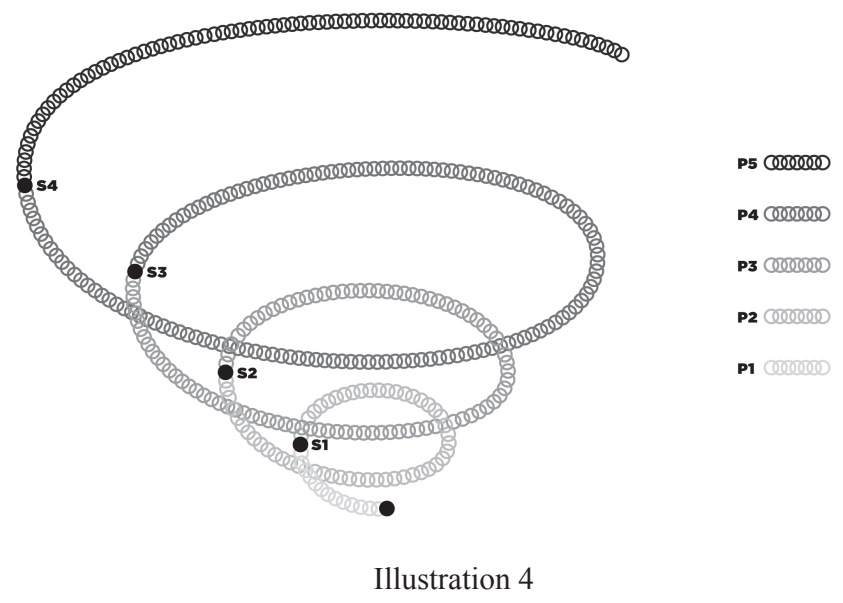

Wir finden in dieser von unten/innen nach oben/außen aufsteigenden Spirale einerseits die verschiedenen Klassen oder Ebenen von Strukturen, in Form der Ringe. Andererseits ist der „Prozeß“ jetzt ein kontinuierlicher: die farbigen Mikro-Spirale-Linien symbolisieren die Hervorbringung von Klassen bzw. den „Prozeß der Benennung des Namens“ ${ }^{\text {"154 }}$. Damit ist das Ziel erreicht, daß uns ,,anstelle einer Hierarchie der Klassen ... eine Hierarchie von Ordnungen der Rekursivität" begegnet. ${ }^{155}$ Die Übergänge zwischen $\mathrm{S}_{1}, \mathrm{~S}_{2}, \mathrm{~S}_{3}$ etc. sind dabei zugleich kontinuierlich und diskontinuierlich zu verstehen: auf der zweidimensionalen Linie selber sind sie - wie diese selber - ein Kontinuum und als Übergänge nicht existent; unter Hinzufügung der dritten Dimension (der Spiral-Raumdimension) wiederum existieren Brüche unter den übereinander liegenden Ringen: von unten nach oben (oben nach unten) gesehen. Die Paradoxie oder Aporie produziert eine weitere Dimension und löst sich darin auf.

Mit dem „Spiral“-Paradigma ist also einerseits das Geschehen ein einheitlicher Prozeß: wir haben eine kontinuierliche Bewegung. Ferner ist das zirkulär-rekursive Moment des Bateson'schen Denkens visualisiert. Vor allem aber illustriert diese Figur die besondere Interaktion zwischen analoger und digitaler Struktur: die Spirale ist beides, kontinuierlich (als Band) und diskontinuierlich (hinsichtlich ihrer gestuften Ringe). Sie beinhaltet bereits eine ,typentheoretische' Struktur (ebenso übrigens wie ein eingerollter Faden - ein Gen-Faden oder auch die Doppelhelix). Ein anschaulicheres und in seiner Rekursivität ,kybernetischeres ‘ Bild für die Gleichzeitigkeit von Prozeß und Struktur läßt sich schwer denken.

Darüber hinaus artikuliert sich in der Spirale, die wir als dehnbar, ausziehbar konzipieren, auch das Variable, Relative der Digitalisierung: den Umstand, daß man in jeder Form und mit beliebigen Abstraktions-Ebenen oder Auflösungs-Skalen strukturieren kann: die Ringe bilden in ihrer Diskontinuität gleichsam kontinuierliche Stufen. Eben dieses ge-

154 Bateson, Ökologie des Geistes, S. 233, vgl. S. 232.

155 Bateson, Geist und Natur, S. 249 


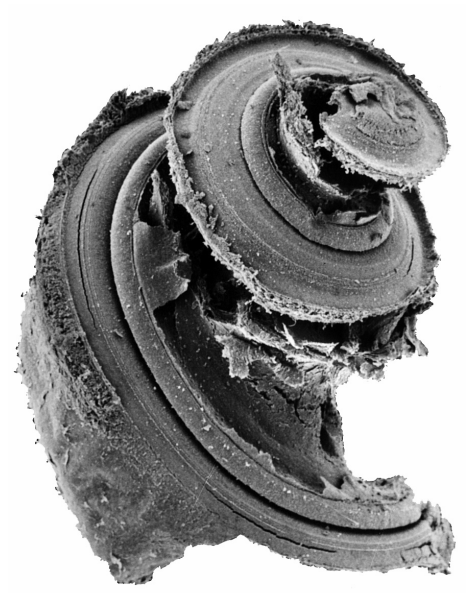

dankliche Paradox wird in der visuellen Darstellung gelöst bzw. aufgelöst: durch Hinzufügung einer weiteren Dimension.

Ein Unterschied dieses Schemas zu dem einer gewöhnlichen Spirale liegt allerdings in ihrem mit jeder neuen Umdrehung wachsenden Radius, was den Umstand symbolisiert, daß der Relevanzbereich auf jeder dieser Prozeß- und Form-Ebenen umfassender wird, wir haben immer abstraktere Informationen und damit weiterreichende Sphären. ${ }^{156}$ Damit ähnelt sie letztlich der Form eines Spiralnebels. Auch die umgekehrte Cochlea, also die Hör-Spirale im Innenohr eines Säugetiers $^{157}$ oder die berühmte Treppe im Museum des Vatikans sind Beispiele für eine solche Figur - die in Natur und Kultur aus guten Gründen immer wieder vorkommt. ${ }^{158}$

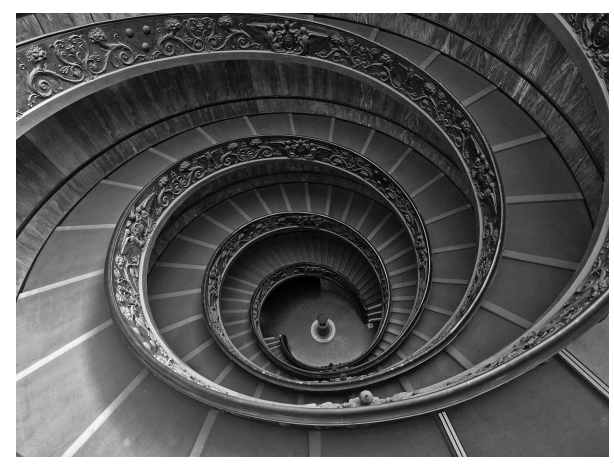

Die hier herauspräparierte „Denkspirale“erinnert damit vermutlich nicht zufällig an jene Figuren in Kosmos, Architektur und Biologie, welchen ein hervorbringender, produzierender (Doppelhelixen, Genfäden) oder auf andere physische (Treppe) oder akustische Ebenen (Cochlea) führender Charakter eigen ist. ${ }^{159}$

Ist die sich verjüngende oder verbreiternde Helix oder auch Schraube also ein Modell, das das Leibniz'sche Kontinuum und die Kantische Gleichheit zweier distinkter Seiten verbindet? Und dies über jenes Begriffspaar (analog und digital), das, in die Philosophie eingeführt von Nelson Goodman, die kontinuierlichen Zeichen, Symbole des Denkens überhaupt erst der epistemischen Betrachtung zugänglich machte? Ist damit, ausgehend von Batesons komplexem Versuch, Prozeß und Struktur oder eben ,analog" und „,digital“ in ihrem rekursiven Verhältnis zueinander zu denken, ein Modell gefunden, das zugleich die hervorbringende (kreative) Progression des Geistes zu symbolisieren vermag wie die Entwicklungsprozesse in der Natur?

156 Vgl. Bateson, Geist und Natur, S. 246.

157 Elektronenmikroskopischer Scan der Cochlea einer Ratte. - Das Bild ähnelt überraschend der Schnecke am Hals einer Geige, eines Cellos oder Kontrabasses. Ferner besteht in der Musiknotation der Violinenschlüssel sogar aus zwei logarithmischen Spiralen. Abbildung Marc Lenoir, http://www. cochlea.org, von Rémy Pujol et al., INSERM and University of Montpellier (11.6.2011).

158 Vatikanische Museen, Rom: „Scala Bramante“: Treppe in Form zweier ineinander gewundener Spiralen einer Doppelspirale.

159 Vgl. etwa folgende naturwissenschaftliche Begründung für das häufige Vorkommen der Figur der Helix in der Natur: http://www.iurc.montp.inserm.fr/cric51/audition/english/sound/fsound.htm (4.6.08). 
Und weiter: Der Umstand, daß bei Leibniz die Richtung des Kontinuums in mehrdeutig war (insofern die unterste und die oberste Stufe auf bestimmte Weise zusammenfielen): spiegelt er sich in der Doppelrichtung der allen Lebewesen eigenen DNA-Doppelhelix, aus der Geist und Natur hervorgehen und deren Stränge gegenläufig zu einander verlaufen? Ist also auch die Denkspirale, als Modell des (nicht nur geistigen) Entwicklungsprozesses im Escher'schen Sinne als in zwei Richtungen gleichzeitig verlaufend zu denken: auf- und absteigend? Haben wir also gleichsam eine Escher-Helix? - Derartige Reflexionen sind natürlich vor allem eines: spekulativ. Sie sind jedoch zumindest eine Emanation der These dieser Studie, daß sämtliche kreativen Durchbrüche aus einem zum Teil sehr komplexen Interagieren mindestens zweier differierender Progressionsformen hervorgehen.

$* * *$

„So what?“ lautet die Überschrift des letzten Kapitel von Batesons einziger Monographie Mind and Nature. Die Frage stellte sich also schon ihm selbst: Warum dieser beträchtliche Aufwand, ein Denkgebäude darzustellen, dessen implizite , theory of everything' sich bis heute systematischen Darstellungen weitgehend entzieht? ${ }^{160}$ Hierfür gibt es aus Sicht dieser Studie vor allem drei Gründe. Der erste ist systematisch und betrifft die evidente Parallele seiner Theorievorschläge zum vorgestellten Kreativitäts-Modell. Der zweite ist historisch und beabsichtigt, die geschichtliche Kontextualisierung jener systematischen Elemente der Informations- und Kommunikationstheorie näher ins Bewußtsein zu heben, die heute vor allem in Bild- und Medientheorien, Philosophie des Geistes und natürlich „KI“" - und Kognitionswissenschaften eine Rolle spielen. So wie Bateson die Kommunikationstheorie für eine Ausweitung der Informationstheorie um die ,, analoge “ Seite hält, so entwickelte Goodman unabhängig davon die Allgemeine Symboltheorie als eine Ausweitung der Sprachphilosophie um die ,, analoge“ Seite. Der dritte Grund liegt damit in den impliziten Herausforderungen, die Batesons „Epistemologie“ für die zeitgenössische Philosophie, speziell die Erkenntnistheorie beinhalten. Dies sind wohlgemerkt die Motive der partiellen Rekonstruktion seiner Absichten; da dies keine Studie über Gregory Bateson, sondern über eine systematische Idee zur Kreativität und ihre historischen und systematischen Ausfaltungen ist, konnte jeder Aspekt nur selektiv verfolgt werden. Um zusammenzufassen: Bateson verwendet (a) die analog-digital Unterscheidung als zentralen analytischen Schlüssel für seine Analyse der Fülle der Phänomene und Begriffe, aber er verbindet mittels seines Zickzackparadigmas (bzw. unseres Modells der Spirale) die - historisch - Alternative von Hierarchie und Symmetrie, die gleichsam zwischen dem Analogen (Prozessualen) und dem Digitalen, „Strukturellen“ oszilliert: auf verschiedenen Stufen. Damit kennzeichnet er (b) das Verhältnis von analog und digital - neu - als

160 Diese Situation betraf auch Bateson selber sowie seine Studenten und Mitarbeiter. „Fast jedes Jahr kam so etwas auf wie eine Klage, die gewöhnlich in Form eines Gerüchts bis zu mir drang. Es wurde vorgebracht, daß ,Bateson etwas weiß, das er uns nicht sagt', oder ,Hinter dem, was Bateson sagt, steckt etwas, aber er verrät nie, was es ist". "Bateson, Ökologie des Geistes, S. 17 f. Entsprechend der Psychiater Jay Hayley, Kollege und Co-Autor in Palo Alto: „wir versuchten herauszufinden, über was in aller Welt Gregory eigentlich sprach. Und er konnte es uns nicht sagen." Zitiert nach Lutterer, Spuren, S. 88. 
ein selber prozessuales; (c) er kombiniert, vereinbart mittels des Zickzackparadigmas die dargestellten Alternativen von Hierarchie und Symmetrie der Erkenntnisformen (Leibniz und Kant) über seine Version des Verhältnisses von Prozeß und Struktur. Schließlich parallelisiert er (d) die geistige und die biologischen Evolution mittels seiner Kombination von Zirkularität und Typentheorie. Dies wurde vorbereitet durch die Kybernetik, welche das Moment des Rekursiven, des Re-Entry (Selbstkorrektur, Eingehen der Information in eine neue Schleife von Information) als gemeinsames Struktur- und Analyse-Merkmal von Leben, Geist und Maschinen ansieht. ${ }^{161}$ Bei Bateson geschieht dies allerdings explizit ohne die restriktiven Momente von Macht, Steuerung und Kontrolle, die historisch wie systematisch häufig mit der Ausdifferenzierung kybernetischer Modelle verbunden sind. ${ }^{162}$

So sieht es an dieser Stelle so aus, als ob letztlich alle großen Kreativitäts, theorien (die selten explizit als solche deklariert werden) dasselbe Verhältnis, zu umschreiben versuchten, von den großen Denkern der Philosophiegeschichte wie Platon und Aristoteles über Leibniz und Kant bis hin zu den Philosophen und Wissenschaftlern unseres modernen Informationszeitalters: das Verhältnis - kurz gesagt - von Endlichkeit und Unendlichkeit. ${ }^{163} \mathrm{Im}$ Abschlußkapitel wird überprüft, welche Konsequenzen sich aus dem Durchgang durch die hier freigelegten historisch-systematischen Formen der Grundfigur für die Frage nach einer philosophischen ,Theorie‘ der Kreativität ziehen lassen.

161 Die Kybernetik parallelisiert also Tier, Mensch und Maschine und impliziert damit von je her eine Anthropologie. Die weitere historisch prominente anthropologische Kennzeichnung, die Parallele von Mensch und Gott bzw. Engel - angeregt ursprünglich ebenfalls durch die frühen Phasen der kybernetischen Bewegung in den Macy-Konferenzen - unternimmt Bateson dann in Bateson/Bateson, Wo Engel zögern.

162 Vgl. hierzu Lawrence S. Bale, „Gregory Bateson, Cybernetics, and the social/behavioural Sciences“ (auch in http://www.narberthpa.com/Bale/lsbale_dop/cybernet.htm (16.8.07).

163 Und die biologische Variante dieses Verhältnisses wäre: Begrenzung/Steuerung und Vielfalt - oder eben: Struktur und Prozeß. 